Portland State University

PDXScholar

$11-21-1979$

\title{
A Critique of Bandler and Grinder's Method of Mapping Representational Systems
}

Leslie E. Goldmann

Portland State University

Follow this and additional works at: https://pdxscholar.library.pdx.edu/open_access_etds

Part of the Cognition and Perception Commons, and the Psycholinguistics and Neurolinguistics Commons

Let us know how access to this document benefits you.

\section{Recommended Citation}

Goldmann, Leslie E., "A Critique of Bandler and Grinder's Method of Mapping Representational Systems" (1979). Dissertations and Theses. Paper 2884.

https://doi.org/10.15760/etd.2878

This Thesis is brought to you for free and open access. It has been accepted for inclusion in Dissertations and Theses by an authorized administrator of PDXScholar. Please contact us if we can make this document more accessible: pdxscholar@pdx.edu. 
AN ABSTRACT OF THE THESIS OF Leslie E. Goldmann for the Master of Arts in Psychology presented November 21, 1979.

Title: A Critique of Bandler and Grinder's Method of Mapping Representational Systems.

APPROVED BY MEMBERS OF THE THESIS COMMITTEE :

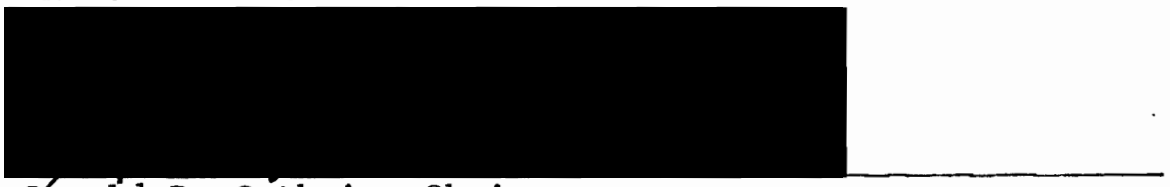

Gerald D. Guthrie, Chairman
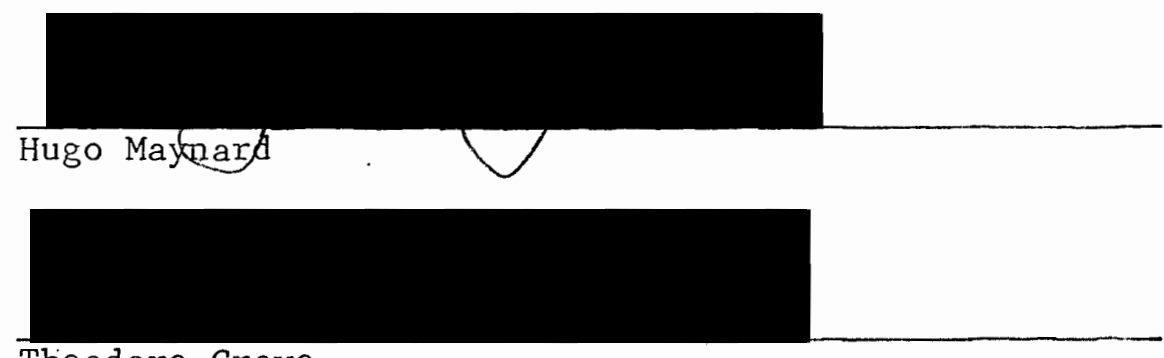

People perceive the world in their own terms: our use of language reflects our perceptions. The way in which we perceive the world and the words we use to reflect that perception Grinder and Bandler (1976) call a "representational system." The authors isolate three types of representational systems, visual, kinesthetic, and auditory, and they present a technique for mapping these systems. These authors state that a sensory preference profile can be mapped accurately and reliably via an individual's use of language. For example, words such as "clear," "see" and expressions of the kind "I get a picture" would 
connote a visual modality. Words such as "feel," "hard" and expressions of the kind "I can't grasp it" would. connote a kinesthetic modality. An individual's profile is the frequency of words used in each sensory modality.

Eighteen $\underline{S}$ s., nine men and nine women, were asked to recount an event in as much detail as possible, noting what they saw, felt and heard. Each $\underline{\text { S.' }}$ 's predicates (verbs, adjectives, adverbs, and meta-

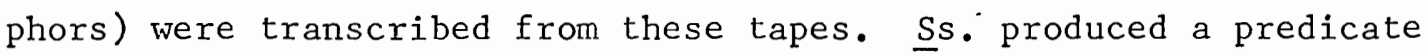
list of between 7 and 75 words, with a mean of 35 words. Fifteen words were selected as presenting a representative sample of $\underline{S}$.'s words. In cases where an $\underline{S}$. produced less than 15 words, all words were included in the test 1 ist. In cases where an $\underline{S}$. produced more than 15 words, 15 were randomly selected. The test 1 ist consisted of

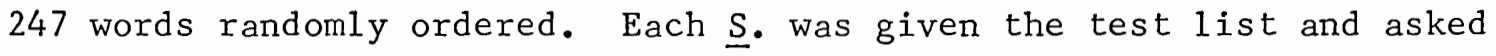
to categorize the words as primarily visual, kinesthetic, or auditory. A profile was drawn for each $\underline{S}$. on all words, his own words, all words minus his own words, and 30 selected words. A profile of how all other $\underline{S}$. perceived the $\underline{S}$.'s own words was also constructed.

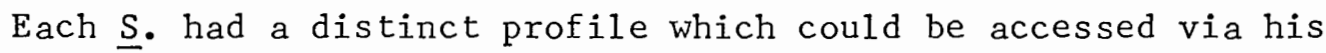
judgments of words. $\underline{\mathrm{S}}$ ''s judgments of all words were biased in the direction on $\underline{S}$.'s judgments of own words; for example, a $\underline{S}$. may perceive his own words and all words as primarily visual. He also perceives another $\underline{S}$.'s words as visual even though this other $\underline{S}$. perceives his own words as primarily kinesthetic. For visual, $r=.40$, significant at the .01 level, and kinesthetic $r=.40$, significant at the .05 level. Significant correlations were found for all Ss.'s judgments of 
each $\underline{s}$. 's own words, $r=.50$ for visual and .72 for kinesthetic. As the number of words judged increased (_15) to 30, 217, and 247, agreement between $\underline{S}$. decreased and no significant correlations were found. Sex of the $\underline{S}$. had no significant effect upon judgments of words. In conclusion, the presentational system of the $\underline{S}$. affects the manner in which the $\underline{s}$. categorizes his own and other $\underline{s}$.'s words. Categorizing words alone is not a reliable method for mapping an individual's representational system. It is biased in the direction of the mapper's own profile. 
A CRITIQUE OF BANDLER AND GRINDER'S METHOD

OF MAPPING REPRESENTATIONAL SYSTEMS

by

LESLIE E. GOLDMANN

A thesis submitted in partial fulfillment of the requirements for the degree of

\author{
MASTER OF ARTS \\ in \\ PSYCHOLOGY
}

Portland State University

1979 
TO THE OFFICE OF GRADUATE STUDIES AND RESEARCH:

The members of the Committee approve the thesis of

Leslie E. Goldmann presented November 21, 1979.
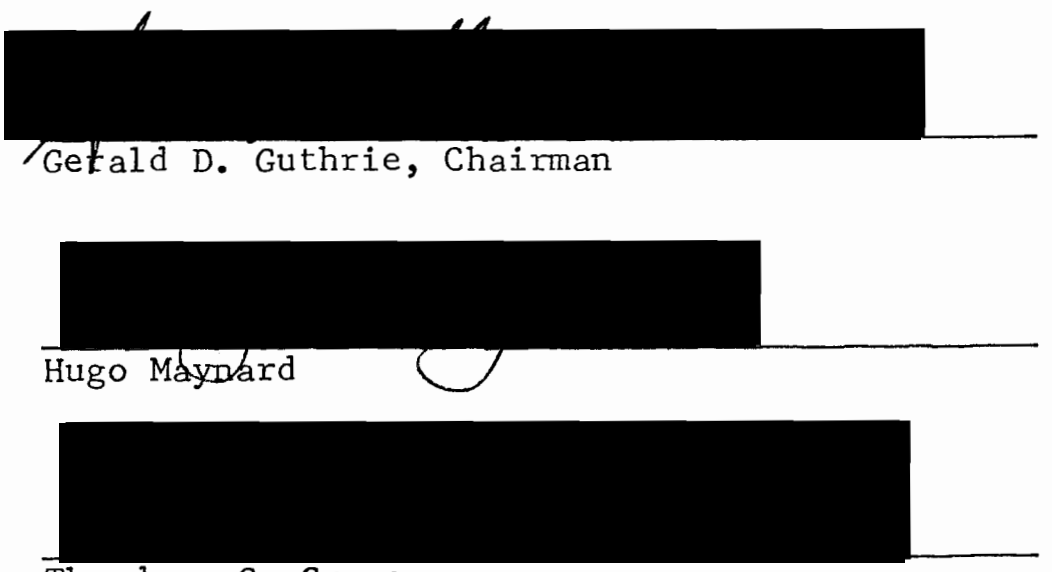

APPROVED:

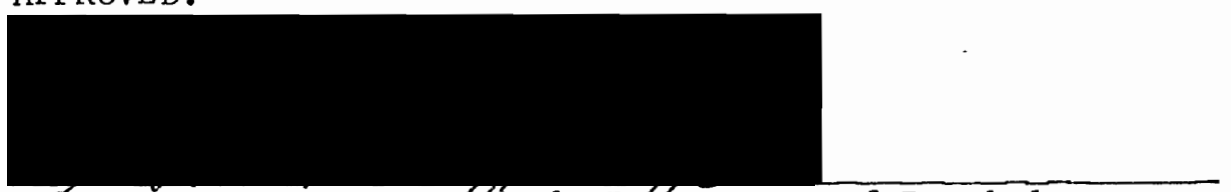

Rort E. Jones, Jr. Alead, Department of Psychology

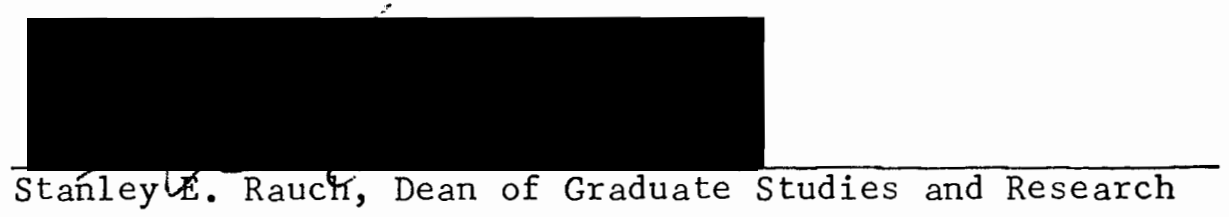




\section{ACKNOWLEDGEMENTS}

Begin, ephebe, by perceiving the idea of this invention, of this invented world The inconceivable idea of the sun

You must become an ignorant man again And see the sun again with an ignorant eye And see it clearly in the idea of it.

\section{Wallace Stevens from "Notes Toward a Supreme Fiction"}

I return to the beginning; to the idea, to that aspect of wonder, "why?," "how come?". I want to applaud those who have understood my confusion and my excitement; Rose, who could look at anything as if it were for the first time, my family, Susan, Tom, and especially Jerry, Hugo, and Ted. 
TABILE OF CONTENTS

PAGE

ACKNOWLEDGEMENTS • • • • • • • • • • • • • • • •

LIST OF TABIES • • • • • • • • • • • • • • • • • • v v

LIST OF FIGURES • • • • • • • • • • • • • • • • • • • vi vi

CHAPTER

I INTRODUCTION • • • • • • • • • • • • • •

Symbolic Representation and

Brain Hemispheres . . . . . • $\cdot$ •

Representational Systems . . . . . . . 10

Language and Perception . . . . . . . 14

Therapy and Metaphor . . . . . . . . 19

II METHOD . . . . . . . . . . . . . . 25

III RESULTS . . . . . . . . . . . . . 28

IV DISCUSSION •. . . . . . . . . . . . 36

$\mathrm{V}$ CONCLUSIONS AND SUGGESTIONS FOR

FURTHER RESEARCH • • • • • • • • • • •

Conclusions . . . . . . . . . . 40

Limitations of the study . . . . . . . 40

Implications for Therapy . . . . . . . 41

Suggestions for Further Research . . . . . 42

LIST OF REFERENCES • • • • • • . . . . • • • • • 45

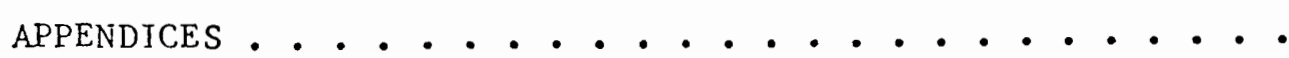




\section{LIST OF TABLES}

TABLE

PAGE

I Percentage of Words Categorized by each

Subject in each Modality . . . . . . . .

II Percent of Subjects by Type and Modality . . . • .

III Scores by Subject on 30 Words and 217 Words . . •

IV Percentage Scores by Subject on Own Words . . . •

V Correlations of VISOTR and KINOTR with

$$
\begin{aligned}
& \text { VISOWN, VIS30, VISALL, KINOWN, KIN30, } \\
& \text { KINALL, KINOTR and VISOTR • • • • • • • • }
\end{aligned}
$$

VI Most Highly Valued Representational System 


\section{LIST OF FIIGURES}

FIGURE

PAGE

1. Mutual Influence of Primary Experience

and Operators upon it . . . . . . . . • •

2. Schematic for Typing Subjects by the

Percentage of Words Ca'tegorized

in each Modality . . . . . . . . . . . 
CHAPTER I

INTRODUCTION

One of the central goals of psychology is to find ways to conceptualize the world. The greater the number of ways we have to understand the same thing, the more precise our understanding of it can be. Two descriptions are better than one, especially if these descriptions can be combined in some manner. An example is binocular vision. The combining of information from the right and left retinas yields increased resolution and precision in judgments of depth. With increased resolution, we are able to perceive several small objects, instead of what may have been mistakenly seen as one large one. In judging distance, we are able to tell how far, and consequently how fast, something is coming with greater accuracy, and thus change our behavior to get out of the way. The combining of these descriptions from both eyes enables us to more precisely detect pattern and predict events.

This same combining of information is useful in the context of the client-therapist relationship. The therapist cannot "see" inside twe sient to determine how he views the world, organizes data, and makes choices. The therapist is presented with a range of verbal and nonverbal communications from which he endeavors to understand the client's conceptualization of the world. The content and style of the client's communications as well as the data to which the therapist 
"selectively attends" will be factors influencing the therapist's understanding of the client's world.

The client presents the therapist with multiple versions of his world, defined by content and context. These are analogous to distinct maps. A map, then, is a way of organizing and presenting perceived reality. What Aziz (1978) has said of cartographic maps can also be said of psychological ones:

Maps are by nature distortions of physical space. Like the child's sketch of the path from home to school in which the house and the school are the, largest elements, all maps contain fabrications that reveal the world view of the cartographer, . . Maps, like language, select certain features and ignore others; and like language, maps are cultural expressions of elements significant to a society. - . . We understand the point of view of the cartographer because we share a language of maps with him. - : Maps from other cultures present us with different distortions, different views of the world, different conventions for the representation of physical space. - . Despite the apparent infinite variety of cultural expressions, similarities in world view and function permit us to compare maps (Aziz 1978).

Several points emerge from the map metaphor: (1) Maps are systematic distortions. They are metaphors, for they are figurative rather than isomorphic. (2) By the inclusion and exclusion of certain elements, they reveal the world view of the cartographer. (3) Maps can be compared, although cultures and individuals may be different, and (4) Language is a map and consequently presents a world view of the speaker or writer.

Metzner (1971, p. 9) writes: "There is an important distinction between a map and a model or a theory. A model or a theory states that 'Man is like this, he learns this way, perceives like this, and.thinks and acts according to these laws.. - 'A map on the other hand is 
pragmatic. - . It says 'Look at it this way and observe the results." A map then is similar to a strategy or a plan. It is at once an interpretive aid and a routine to be followed. Miller, Gallanter and Pribram (1960) define plan as "any hierarchal process in the organism that can control the order in which a sequence of operations is to be performed." There must then be a plan for the drawing of maps. The discussion of maps then will include their characteristics and also how they might be drawn.

Each individual draws a distinct map (of what he believes the territory to be) based upon his sensory experience. This map is not such that it is easily discernible to anyone who might wish to read it (or even to the mapmaker himself). It must, however, reflect in some manner those elements that are important to the individual, his strategies and orientation. The manner in which an individual communicates his map is at once a message about the map and a map in and of itself (i.e., a message and a metamessage). Further, any interpretation of the client's map on the part of the therapist will be influenced by the therapist's own map. While each map is as distinct as an individual's experience, it is proposed here that there are regularities to how maps are drawn and that these cartographic strategies are reflected in an individual's use of language and in his world image. .Kezlikry (1955, p. 12) writes:

Man creates his own ways of seeing the world in which he lives. The world does not create them for him. He builds constructs and tries them on for size. His constructs are sometimes organized into systems, groups of constructs which embody subordinate and superordinate relationships. The same event can of ten be viewed in the light of two or more systems. Yet the events do not belong to any system. 
Kelly is referring to a system of personal constructs, equated here with the concept of maps and world image: multiple versions of the same thing.

How one conceptualizes the world, the distinctions between first order and second order reality, between what is "actually" out there and what we perceive, has been grappled with by innumerable philosophers and scientists: Hume, Nietsche, and more recently Sartre, Polanyi, and Bridgman. How we know what we know touches the core issue of subjective reality. As Bateson (1979, pp. 87-88) writes: "Epistomology is always and essentially personal. The point of the probe is always in the heart of the explorer." While the nature of subjective reality is an elusive philosophical issue, its relation to psychotherapy is straightforward and pragmatic.

Epictetus long ago stated: "It is not the things themselves that worry us, but the opinions we have about those things." It is our opinions, our maps, our metaphors that are the stuff of therapy. The world itself does not change. Consequently in order to elicit a change, the therapist must first discover, understand, and finally influence this world image. This world image can most easily be reached via the client's use of language. The conceptual base of the following research is that there is a reflexive interaction between an individual's use of language and his world image. Given the sensory basis for perception and language, differences in the use of language may indicate biases in the selection and organization of stimuli.

Grinder and Bandler (1976, p. 6) have suggested that an individual's strategies for mapping the world are sensory-based and that 
these strategies are reflected in an individual's use of language: such that "seeing is believing," "that sounds right," or "I can't grasp it" are accurate representations of how an individual maps his world. These strategies are related to which sensory modality an individual relies most heavily upon. For example, a skilled musician would be expected to make minute distinctions of timbre and pitch. These distinctions might be reflected in his use of language. The type and frequency of particular words (possibly auditory, then kinesthetic, then visual) would be indicative of his sensory preference profile. An analogy would be the sensory homunculus. The area ascribed to each part of the homunculus is a function of the tactile discriminations that can be made on that part of the body. The thumb of the homunculus is disproportionately large because the discriminations that can be made with the thumb are correspondingly fine. An individual's use of language maps not only how fine a discrimination he can make in a given modality, but also gives the frequency of words of one modality with respect to the others: this is the extent to which he relies upon that modality in perceiving the world. We will return to their system later.

A plethora of techniques have been proposed for therapists to detect and outline a client's map of the world, from role playing to Cice association to behavioral analysis. Major proponents in the area of Gestalt therapy (Polster and Polster 1973; and Fagan and Shepherd 1970) have underscored the merits of content-free techniques. These, they suggest, minimize the effects of the therapist's own map 
by relying upon the client's style of communication and how and what

language is used. Watzlawick (1978, p. 140) writes:

One of the most basic differences between traditional psychotherapy and certain brief therapeutic (including hypnotherapeutic) procedures is the fact that in the former the patient is first taught a new language, the language of the theory his therapist subscribes to. The learning process is of necessity time consuming and greatly contributes to the length of the classic therapies. - . The hypnotist learns and employs the language of his client; the term language here being meant metaphorically and literally. . . the therapist not only does his utmost to arrive at an understanding of his client's values, hopes, fears, prejudices, in short, his world image, as quickly and as completely as possible, but he also pays attention to the actual language of his client and utilizes it in his own verbalizations. . . the semantics of a person reveals the sensory modalities with which he primarily perceives the world.

The therapist, then, not only chooses different words for a child and an adult, but also tailors his language to coincide with the client's perception of the world. This presupposes for Watzlawick and for Grinder and Bandler that the therapist can accurately detect the client's primary sensory modality.

Representational systems are indications of an individual's world image. If one accepts the idea that a change in world image is necessary for a successful therapeutic outcome, then accurate mapping of representational systems is useful if not essential.

Watzlawick (1978, p. 45) has suggested an interdependence between language, world image, hemispheric functioning and representational systems. To use Bateson's (1979, p. 68) terminology, language is the "pattern which connects." The following sections will explore the relation between language and each of the above concepts, as well as presenting a formal model of 'representational systems. Finally, these language patterns will be discussed in the context of therapy. 
SYMBOLIC REPRESENTATION AND BRAIN HEMISPHERES

It is well known that man uses two kinds of languages. One is objective, logical, analytic, the other expressive and metaphoric; the language of imagery and synthesis. The former follows the rules of linguistic logic, grammar, semantics and syntax. The latter does not follow these rules and is the language of dreams and fantasies. In communication theory a similar difference exists between digital and analog modalities.

Bateson (1979, pp. 227-228) defines digital "as signal . . if there is discontinuity between it and alternative signals from which it must be distinguished. In contrast, when a magnitude or quantity in the signal is used to represent a continuously variable quantity in the referent, then the signal is said to be analogic." Examples of digital communications are "yes,". "no," or "the cat is on the table."

A client coming to see a psychotherapist will use some kind of verbal 1 anguage to describe his problem, containing both statements of fact (digital) and metaphoric or analog communications. Client statements can be interpreted by the therapist in turn as either digital (frequency of a given type of behavior) or as symbolic. In the instance of a washing compulsion, the therapist could record a baseline of number of times/day, or inquire as to the metaphor this gesture implied. Often a client will speak in precise and logical terms which can easily be transformed into digital information. However, a client may use symbolic or metaphoric language and translating 
these communications into digital form would be analogous to counting words in a poem.

Analog and metaphoric communication have multiple referents and deal with resemblance and relationships between things. Each message is framed in the context of other messages. Included in this style of communication are play, ritual, and all forms of art (Haley 1976, pp. 82-85). The analog can be expressed in verbal 1 anguage as simile or metaphor.

There does not appear to be a continuum from digital to analog communications; for example, paintings in the Pointillist School were not understood as a myriad of individual dots of color, but as a gestalt or form. Problems of description arise when information is perceived in a manner different from the way in which it was sent or intended to be understood.

Watzlawick (1978, p. 16) writes: "The fact that there exist these two 'languages' suggests that they must be representative of two very different world images, for it is known that language does not so much reflect reality as create it." Evidence for these two differing kinds of world images can be drawn from the asymmetrical functioning of the brain. The research on hemispheric asymmetry and dominance is quite extensive and will only very briefly be mentioned tere. The reader is referred to Milner (1970); Galin (1974); Sperry and Gazzaniga (1967).

Geschwind (1967) found that individuals with extensive left hemisphere lesions were able without difficulty to name Roman numerals, but could not name words or Arabic numerals. He writes that these 
"two tasks which appear quite similar, such as reading a word and reading a number, may in fact be carried out in quite different ways by the nervous system." Geschwind also found in patients with commissurotomies that while they would incorrectly name an object, they would, however, have correctly perceived it. This was noted because they could pick the object out from a group of objects with their left hand, would handle it correctly, and could draw the object with their left hand that had previously held it. This they could not do with their right hand.

The observable consequences of hemispheric disconnection suggest that we actually possess two brains that can function independently of each other. They do not react in an identical manner but respond to those stimuli which fall into their domain of competence. They may in fact possess two different languages and any attempt to influence any one hemisphere should be made in that hemisphere's "1 anguage."

'Korzybiski's famous distinction that the map is not the territory has ramifications on many levels. On one level it asserts that what.. we perceive is not the thing itself; when we see a tree, there is no tree in our brain. All communication, thought, and perception involves the transformation or coding of primary sense data with some form of name or. 1abel.

Bateson (1979, pp. 30-31) and Jaynes (1977) state that the distinction between the name and the thing named is only made by the dominant hemisphere, this distinction being unavailable to the symbolic or affective hemisphere. Consequently, while the dominant hemisphere 
will be able to make the distinction that a flag is a sort of name for a country, the non-dominant hemisphere perceives flag = country and may respond with rage when the $\mathrm{flag}$ is trampled.

Bateson proposes that a map is simply a sumnation of differences, or a way of organizing the differences in the territory. The various procedures for encoding these differences, digital or analog, lead to differences in maps or in logical types. Substantial experimental evidence exists for differences in hemispheric maps.

How then are these two "1 anguages," hemispheric asymmetry, and the differing world images that they imply, to be integrated into a coherent whole? Watzlawick (1978, p. 45) suggests that "The translation of perceived reality, this synthesis of our experience of the world into an image, is most probably the function of the right hemisphere. To the left half, presumably, goes the task of rationalizing this image, of separating the whole into subject and object. . . ." In this light it is also probable that the right hemisphere shapes the world image as presented by the sensory modalities and that the language of representational systems is similarly the language of the right hemisphere.

\section{REPRESENTATIONAL SYSTEMS}

It is now clear that man's perceptual and linguistic systems are closely linked (Clark, Carpenter, and Just 1973). Our experience of the world is not a direct template of the world "as is" but is filtered and selected by our five senses: vision, audition, kinesis, taste, and smel1. At any one time, our attention is focused upon one or several 
of these sense modalities to the exclusion of the others. The following is a formal model proposed by Grinder, Delozier and Bandler (1977, pp. 21-39) to describe an individual's sensory experience and its relation to language. This model consists of four components (or a 4-tuple) and operators (functions performed) on it. It should be noted here that these authors have not specified the particular mechanics of the operators, nor the processes for encoding and representing their model in memory.

The 4-tuple consists of $\left(V, K, A_{t}, 0\right)$,

$$
\text { where } \begin{aligned}
\mathrm{V} & =\text { Visual } \\
\mathrm{K} & =\text { Kinesthetic } \\
\mathrm{A}_{\mathrm{t}} & =\text { Auditory tonal } \\
0 & =\text { Olfactory stimuli }
\end{aligned}
$$

Taste has been excluded from this model. Were an individual to receive no auditory imput, the value of $A_{t}$ would $=\varnothing$. The origin of $V, K, A_{t}$, or 0 stimuli may be internal or external; this is signified by the superscripts e or i.

Language is considered to be secondary experience and the relation between it and the primary sensory experience of the 4-tuple is represented by an $A_{d}$ (auditory digital) operator upon the 4-tuple. $A_{d}-\left(V, K, A_{t}, O\right)$. Language is noted as an operator distinct from the basic variables of experience because it is of a different logical type. Language can express negation or tense, unavailable in primary sense data. 
The relation between a word or set of words and the 4-tuple or set of 4-tuples it represents is called a Complex Equivalent. The Complex Equivalent $A_{d}=$ Rain =

$\mathrm{K} \quad \mathrm{A}_{\mathrm{t}} \quad 0$ sight of drops wet feeling sound of drops smell of wet pavement gray sky hitting thunder

The particular values of the 4-tuple in this instance may be fairly consistent from person to person, and this is what makes language a reliable means of communication. For other Complex Equivalents (words or phrases; e.g., freedom, vacation), agreement between individuals would be less consistent and consequently these words have more ambiguous meanings.

One of the tasks of 1 anguage is to assign phonological sequences $\left(A_{d}\right)$ to the 4-tuples of our experience. The assignment of sound to 4-tuples is one of the most pervasive ways in which language influences (at the most unconscious levels) our experience. We come into the world with words waiting for us already standing for things and experiences. Certain 4-tuples and not others are named, thus organizing experience along certain 1 ines and not others. For example, anthropologists (Whorf 1956; Sapir 1956) have noted how different cultures partition the continuous gradation of the color spectrum.

Gordon (1978, p. 215) has suggested that our "selective attention" ". . is not always ad hoc . . each individual learns to depend'upon one sensory system or another as a means of perceiving and understanding the world." This selective attention would be represented by the kind 
and number of 4-tuples that would represent the individual's experience and by the $A_{d}$ operator upon these 4-tuples.

The sense modality which the individual most favors is his/her Most Highly Valued Representational System, M.H.V.R.S. This is the "R" operator upon the 4-tuple for that person.

Experience at any point in time will have at least some visual, auditory, kinesthetic, and olfactory components to it (either internal or external in origin).

For example:

I sit here and smell dinner cooking. I also "see" what is in the pot and listen to my stomach growl. One way this could be represented is:

$\begin{array}{cccc}\mathrm{V} \text { - Internal } & \mathrm{K} \text { - External } & \mathrm{A}_{t} \text { - Internal } & 0-\text { External } \\ \text { imagined sight } & \text { feel of chair } & \text { growl } & \text { smell of food } \\ \text { yielding } A_{d} \text { - waiting for dinner } & & \end{array}$

Each of these combined at any point in time will yield an $A_{d}$ or language representation. The $\mathrm{R}$ operator can be applied both to the primary 4-tuple and to the $A_{d}$ language representation of it, yielding what is available to the individual as conscious experience at that moment. If an individual's conscious experience consists very largely of visual imput (either internal or external) while auditory imputs are given low priority, this would directly affect his choice of words and his words in turn would in some fashion direct his perceptions; consequently, two individuals may have the "same experience" in terms of the primary 4-tuple. As a result of the $A_{d}$ and $R$ operators upon 
that 4-tuple, they will have differing conscious experiences and ascribe different words and meanings to those experiences.

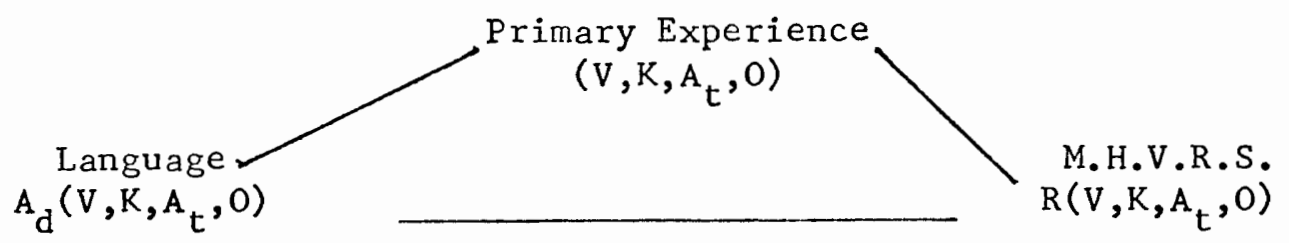

Figure 1: Mutual influence of primary experience and operators upon it. It is this author's interpretation of Grinder, Delozier and Bandler's model.

\section{LANGUAGE AND PERCEPTION}

The research concerning selective attention is extensive. The etiology of its development has been less wel1 explored. On a common sense level it must surely be explained by what has worked, essentially the definition of "reliable." Developmental studies by Blank and Kling (1970); Milne (1969); Rudel and Teuber (1964); and Millar (1972) suggest that the precision and reliance of specific intermodal judgments is age-dependent. Spencer (1970) has found that inter- and intra-modal matching ability of elderly persons is closely related to those of children. Millar (1972) and Treisman (1969) both conclude that in many of these areas of perceptual and psychophysiological functioning the aging process produces a functioning level and a selective reliance in the elderly similar to those of children.

Differences between individuals in the perceptions of their environment can be explained on two levels. The first level includes selective attention to sensory imput, and variations in experiences 
with sensory imput. The second level is that of meaning. The firing of neurons is a digital communication, giving information not about the environment, per se, but about the sensory organism to which they are connected. This pattern of neural firing is only meaningful when compared to other patterns. Until one is taught how to read, any pattern of letters is as meaningful as any other.

Until a child has touched a needle, it is neither sharp nor dull, but does have form and color. Once the needle has been touched, the form and color are associated with sharp/pain. Later, when the child hears the word "needle" it is a meaningless sound until associated with the object itself or an image of it. Later again, the child is presented with the written word NEEDLE; this too is meaningless until associated with the sound or the picture (Gordon 1978, pp. $215-216)$.

The association of perceptual experience occurs as both interand intra-sensory modalities. The associations in the above example are as follows:

(1) V with K (Sight of needle with touch)

(2) A with $V$ (Sound of "NEEDLE" with sight of object)

(3) V with $\mathrm{V}$ and/or A (Sight of "NEEDLE" with sight of object and sound of "NEEDLE")

These associations do not occur on the modality level but on the level waf submodality.

In the theory of sensory attributes the modalities comprise the first level of analysis. A perception of a meal, for example, consists of visual, tactual, gustatory and olfactory sensations. The second level of analysis is a catalog of sensory attributes within each modality. Four sensory attributes are distinguished: quality, intensity, extension, and 
duration. It is assumed that attributes are characterized by independent variation, or, in more operational terms that two sensations in the same modality can be judged the same with respect to one attribute while other attributes vary. . . In the visual modality, the quality of a sensation is its hue, the intensity is its lightness, the extension is its apparent area, and the duration is its apparent duration. (Miller, Johnson-Laird, 1976, p. 15.)

The child, then, associates the submodalities of the needle's appearance with the specific kinesthetic submodalities associated with sharp/pain. The child learns the specific visual correlations of color, shape, etc, associated with the needle such that he is not afraid to touch, for example, a silver line.

One of the fundamental problems confronting cognitive psychology and linguistics is how these associations of submodalities, 4-tuples, and Complex Equivalents are represented and retrieved from memory. How they are structurally represented has produced long and hard debate (Amarel 1968). Models have ranged from holographic representation (Pribram 1971, p. 140) to propositional (Anderson and Bower 1974, pp. 155-159). Each of these models (and there are many others) are to some degree perceptually based, and what is encoded, albeit a sentence, is the perceptual description of the scene. Both in the evolution of man and in the development of the child, the ability to encode perceptual information precedes that of linguistic information.

Research by Moeser and Bregman (1972) on the learning of miniature "languages" and by Bever (1970) have led Anderson, and Bower (1976, p. 154) to state: " . . language attaches itself parasitically to this underlying conceptual system designed for perception - . natural languages can be learned initially only because their 
organization corresponds . . to the perceptual organization of the perceptual field." The organization of this perceptual field further influences the acquisition of grammatical relations and syntactical organization. Language is essential for the development of abstract concepts; however, the structures that develop in memory are never free of their perceptual origins. A quote from Whorf illustrates:

I grasp the thread of another's argument, but its level is over my head, my attention may wander and lose touch with the drift of it, so when he comes to the point, we differ widely, our views being indeed so wide apart that things he says appear much too arbitrary or even a lot of nonsense (Anderson and Bower 1976, p. 155).

Within this framework it is possible to ask the question whether (1) the submodal associations are."pre-wired" with basic operating instructions (such as "pointed/pain" or "red/hot") which are summed with other contextual information to produce an experience, or (2) whether experience is stored as contextual information to be, in turn, matched with sensory experience. This first proposition would suggest that there is a bias toward certain associations. These associations are not context dependent, but summed with contextual information and are then interpreted as an "experience." The second proposition would suggest that sensory experience is stored "in context," possibly as a form of template. This template is matched with sensory experiences. Evidence exists to support both propositions.

Melzack (1973) gives numerous instances in which pain is a context-dependent phenomenon. Pribram (1971, p. 45) suggests that configurations of submodal interactions are stored holographically. Most of these associations are context dependent, as in the case of 
pain. However, there is evidence that certain associations such as red/hot are not context dependent, but are "pre-wired." For instance, most. people consider red to be a warm color regardless of whether it is the red of a dress, an apple, or a flame. Here there is a patterned relationship between color and temperature. This may or may not exist between other sensory submodalities (Gordon 1978, p. 226).

On the level of modal interactions, Masterton and Berkley (1974) have presented evidence that the motor, association, and sensory areas of the cortex do not function discretely, but affect one another. Stimulation of the visual area may produce activity in the auditory or kinesthetic projection areas. Studies by Bach y Rita (1972); Eccles (1966); and Pribram (1971) give physiological evidence to the already substantial evidence in the area of perception that sensory modalities do interact (Mainwaring 1932; Jordon 1964; Gellhorn 1964). Additional evidence regarding these interactions is available in the area of synthesia (Gibson 1969; von Bekesy 1959; Wicker 1966; Erickson, Rossi and Rossi 1976).

Although we have been speaking about sensory modalities and the interactions between them, the influence of language here again is. persuasive. Language, in a very real sènse, determines not only what we see, feel, taste, hear, and smell, but also the meaning we ascribe to it and the manner in which we communicate that meaning. How perceptions are coded, stored and retrieved are functions of language. This manner of coding (digital, analog, templative) leads to the. creation of different logical types, and hierarchies between the name and the thing named, member and class, etc. These'differences are 
essential for the creation of maps and metaphors. The creation of metaphor and the communication of it lead back to the context of therapy.

\section{THERAPY AND METAPHOR}

Ryle (1941) has defined category mistake as "the presentation of facts as if they belonged to one logical type or category . . when they actually belong to another." It is this pretense, make-believe, or "as if" quality that is essential for metaphor. When this "as if" is lost, as in the case of certain kinds of schizophrenia, the metaphor is taken literally and leads to subsequent miscommunications. Therefore, the metacomunication "this is metaphor," as in "this is play". or "this is ritual," is necessary. The use of metaphor involves, then, "both awareness of duality of sense and pretense that two different senses are one" (Turbayne 1962, p. 18).

The confusion between logical types is pervasive and for the most part is accepted as simply a part and parcel of language. As Turbayne writes:

We see on her face not only a look of gladness and a blush of shame, but also gladness and shame. We hear not only sounds but words, propositions, lectures, bells, and aircraft. We see not only colored shapes, but words, meanings, and the point of jokes. Ice not only feels cold: and water wet: they do indeed look cold and wet. There is not much lihevess vetween . . a blush and shame, between sounds and a proposition, . . between a colored shape and a joke or between a look and a feel, except in a name... we do not take our words literally for we know language itself is framed (1962, p. 77).

Yet given the perceptual basis of 1 anguage we may be mistaken by discrediting this literal sense. It is this literal sense that is the basis for our internal metaphors and map-drawing directives. 
Reusch and Bateson (1951); Satir (1967); Haley (1976); and Watzlawick (1978) have all defined psychopathology as disturbances of communication. Terms such as delusion, hallucination, withdrawal, and elation imply either distorted perception or unintelligible transmission. Psychotherapists believe that contact with a client in the context of a social situation (individual, family or group) has a therapeutic effect. These interactions certainly fall in the realm of communication; however, exactly what is communicated and what the specific variables are necessary for therapeutic change to occur have been very much open to question.

"When all participants adhere to the same system of communication, a spontaneous give and take develops, because implicitly these participants know how to communicate, although explicitly they are frequently unable to formulate their methods of communication" (Reusch and Bateson 1951, p. 87). Hence there is a tacit understanding of frames, rules or a metacommunication of "this is how we will talk." Bateson (1972, p. 190) puts forward the following propositions: (1) Certain types of pathology are characterized by anomalies of the client's handling of frames. (2) To a great extent, psychotherapy depends upon the manipulation of these frames, and ( 3 ) It is possible to describe what happens in therapy as the interaction of how clisent and therapist handle frames.

The dependence of psychotherapy upon the manipulation of frames follows from the fact that therapy is an attempt to change the patient's metacommunicative habits. Before therapy, the patient thinks and operates in terms of a certain set of rules. - . In the process of therapy, there must have been communication at a level meta to these rules. There must have been communication about a change in rules (Bateson 1972, p. 191). 
This change in rules or frames may most simply be seen as a change in metaphor. Haley (1976, p. 99) puts the idea most succintly: "The symptom is not a 'bit' of information, but an analogy. . . The goal of therapy is to change. . metaphor." We have returned to Epictetus.

How then is a client's metaphor to be altered?

How does it happen that in the interchange of messages between two persons with differing systems of codification and evaluation, a change occurs in the system of codification and evaluation of either one or both persons? This problem touches upon the paradox that, at a given instant, an individual can only emit or receive messages structured appropriately for his communication system. - . All other messages must be supposed to remain either unperceived, unintelligible, or misunderstood (Reusch and Bateson 1951, p. 82).

The task of the therapist, then, is to master and match a number of different communication styles. Central to this is speaking the client's language or meeting him at his metaphor. If a client's predicates are a representation of his rules for mapping and a metaphor for understanding the world, then matching representational systems will be an effective way of understanding the client's map, building trụst, and changing his metaphors.

The use of metaphor and analogy has been central to the conduct of therapy for both behaviorists and psychoanalysts. The directive to "free associate" is essentially one to abandon digital communication. In the case of behavior therapy the therapist may draw his own analogies from an ordered 1ist of the client's "anxiety" situations. The client here responds only with digital communications as to whether he is anxious or not. Thomas Stampfl's implosive therapy is an example 
of building extreme metaphors. These metaphors are not graded. The intent is to overwhelm the client with grotesque or at times absurd metaphors. If the client becomes more anxious, this increases the power of the metaphor. The client can only "recover" by becoming less anxious. This in many cases takes the form of laughter, possibly at the absurd metaphors.

In the case..of verbal conditioning therapies, the client offers analogies about his life and the therapist selectively reinforces them with digital communications (Haley 1976, pp. 85-87).

Finally, and these may be the most powerful forms of communication, the therapist may tell jokes, puns, myths, fairy tales or construct metaphors specifically-tailored-to the client's situation (Gordon 1978; Watzlawick-1978). Hypnosis has proven itself as an extremely effective tool in changing world image. This is due to its utilization of ambiguity, unspecified verbs, aphorisms, chiasms, and all manner of figurative language. All of the above language patterns are the exclusive domain of the right hemisphere--wherein resides the individual's world image. Consequently, any technique (and these are limited only by the ingenuity of the therapist) that can talk to the right hemisphere in its own language has the potential to elicit change in the individual's maps and metaphors.

For an analysis of these language patterns, the reader is here referred to the works of Milton Erickson. One extension of Erickson's work in recent times which offers an approach to therapy in the modes described above comes from Grinder and Bandler (1976). Their approach 
begins with a technique for mapping sensory modalities (representational systems).

They state that: (1) An individual's semantics accurately reveal his sensory preference, and (2) An individual has a Most Highly Valued Representational System (M.H.V.R.S.). In determining M.H.V.R.S., Grinder and Bandler focus upon the visual, kinesthetic, and auditory sense modalities:

In order to identify which of the representational systems is the client's most highly valued one, the therapist needs only to pay attention to the predicates which the client uses to describe his experience. In describing his experience, the client makes choices (usually unconscious) about which words best represent his experience. These words are . . called predicates . . (and) appear as verbs, adjectives and adverbs . . very little of natural language communication is metaphorical. Most people in describing their experiences, even in casual conversation are quite literal. Comments such as "I see what you're saying" are most of ten communicated by people... whose most highly valued representational system is visual (1976, pp. 9-11, emphasis added).

Examples of this categorization are:

$$
\begin{array}{ll}
\text { "black } & =\text { visual } \\
\text { "forward" } & =\text { visual and kinesthetic } \\
\text { "yell" } & =\text { auditory } \\
\text { "image" } & =\text { visual } \\
\text { "smooth" } & =\text { visual and kinesthetic } \\
\text { "I can't get a handle on it" } & =\text { kinesthetic } \\
\text { "That sounds right" } & =\text { auditory }
\end{array}
$$

A number of these words have multiple categorizations. Grinder and Bandler note this ambiguity and instruct the therapist to resolve it as follows: "Ask yourself what you have to do to verify the description given by the predicate and its sentence." This writer questions whether this is sufficient to resolve the ambiguity. 
One questions whether different words will be found ambiguous by different individuals, and what are the determinations of how this ambiguity will be resolved. These are the questions of this research. What is known about this kind of mapping and its relationship to therapy is anecdotal in nature. Bandler and Grinder (1975, pp. 20-21); Gordon (1978, pp. 94-96); and Watzlawick (1978, p. 141) give numerous examples of how this technique can be used in therapy. Nothing is stated, however, as to whether different therapists will make similar determinations. It is the concern of this thesis to subject a small portion of this anecdotal knowledge to empirical inquiry. More specifically, do the techniques of mapping representational systems as proposed by Grinder and Bandler (1976, pp. 6-12) provide valid and reliable measures of a client's sensory preference? The hypotheses to be tested are:

H1 - Each subject will have a sensory profile with a dominance in one sensory modality.

H2 - Subjects' judgments of each other's sensory profile will be biased in the direction of their own profile.

H2 - Sex will not correlate highly with individual modalities. 
CHAPTER II

METHOD

Eighteen $\underline{S}$ s., nine men and nine women, were contacted in person and asked to participate in an experiment concerning representational systems and language. The $\underline{S}$. were selected from a wide range of educational backgrounds and occupations. The age range was $21-45$ years. Each $\underline{\text { S. }}$ was asked to arrange an appointment with the $\underline{E}$. , either at the $\underline{E}$.'s office or at the home of the $\underline{S}$.

Office Setting. The office was a small room in which there were two chairs, a desk and numerous pictures on the walls. There was a tape recorder on the desk and the $\underline{S}$. was asked to sit facing $i t$. After an exchange of greetings, the $\underline{S}$. was handed a card with the following instructions:

IN TWO OR THREE MINUTES, PLEASE DESCRIBE IN AS MUCH DETAIL AS POSSIBLE, AN EVENT: NOTING WHAT YOU FELT, SAW, AND HEARD. I WILL LEAVE THE ROOM AND RETURN IN A FEW MINUTES. THANK YOU. LES

There were six variations in the instructions, accounting for the different orderings of "SAW, FELT, AND HEARD." The $\underline{E}$. then instructed the S. how to operate the tape recorder and left the room to return in 5 minutes. 
Home Setting. Because of scheduling difficulties, it had been arranged that nine $\underline{S}$. (half) were seen in their homes. The E. endeavored to duplicate as much as possible the office setting: finding a small room, seating the $\underline{S}$ : in front of the tape recorder and minimizing distractions.

From the tapes that the $\underline{S}$. recorded, the E. transcribed all verbs, adjectives, adverbs, and metaphors. A list of words was compiled for each $\underline{S}$. From these lists, a composite or test 1 ist of 247 words was drawn. Ss. produced word lists ranging from 7 to 75 words. The mean number of words produced was 35. Fifteen words were selected as presenting a representative sample of each $\mathrm{S} s$.'s words. In cases where the $\underline{S}$. produced less than 15 words, all words were included in the test 1ist. In cases where a $\underline{S}$. produced more than 15 words, 15 were randomly selected. The words were then randomly ordered on a test list. The test form contained 300 lined spaces. The 53 blank spaces were randomly interspersed between the words; see Appendix A. The word 1ist, see Appendix B, contains 43 duplicate words or similar words; see Appendix C. These duplicate, words were retained in the test list to maintain the frequency of their occurrence in the $\underline{S}$. population's natural language.

The Ss. were recontacted from $2-6$ weeks after the initial

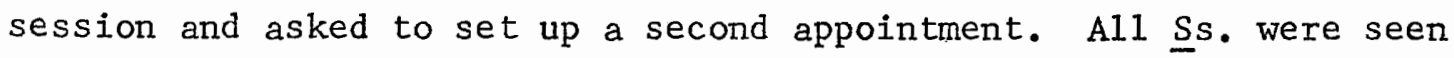
in their original setting. Each $\underline{S}$. was given the test list with the following instructions:

FOR EACH OF THE WORDS ON THE PAGE(S) DECIDES WHETHER IT IS PRIMARILY AUDITORY (CONNOTING HEARING), VISUAL (CONNOTING 
LOOKING OR SEEING), OR KINESTHETIC (CONNOTING FEELING OR TOUCH). PUT A CHECK UNDER THE COLUMN A, V, OR K. IF YOU HAVE A 2ND CHOICE, PUT A '2' IN THAT COLUMN. THANKS.

EX.

LOUD

GLANCE

COLD

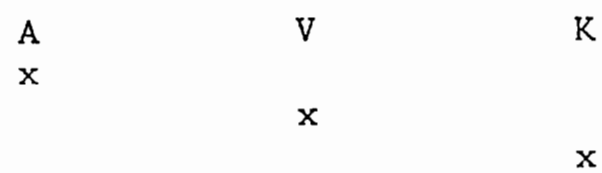

There were six variations in these instructions, within both the text and example; the ordering in the example followed the ordering in the text. There were also six variations in the ordering of the columns to be checked on the test list. In both the first and second sessions, the $\underline{S}$. was randomly assigned to one of these six conditions, yielding $3 \underline{S} s$. per condition. The $\underline{E}$. asked the $\underline{S}$. if there were any questions regarding the instructions. After these (jf any) have been answered, the $\underline{E}$. left the room, asking the $\underline{S}$. to call him when he/she finished taking the test. 
CHAPTER III

RESULTS

H1: Each subject will have a sensory profile with a dominance in one sensory modality.

The first question that one needs to ask is "How is this profile to be determined?" Bandler and Grinder propose that this profile can be mapped via the categorization of predicates into Visual, Kinesthetic, and Auditory. For this profile to be reliable, the categorization of predicates must be consistent over individuals performing the categorizations. Do these 18 Ss. then categorize the 247 words in the same manner? If the answer is "yes," then using predicates to map an individual's sensory profile is a reliable measure. If the answer is "no," two possibilities arise: 1) An individual cannot be categorized via his use of predicates of 2) An individual can be categorized but the profile will differ depending upon the individual doing the judging. Table 1 presents Subject's categorization of all words by modality. Primary and secondary responses for all words by subject are found in Appendix D. 
TABLE I

\section{PERCENTAGE OF WORDS CATEGORIZED BY EACH}

SUBJECT IN EACH MODALITY

\begin{tabular}{rrrr} 
Subject & Visual $\%$ & Kinesthetic $\%$ & Auditory $\%$ \\
1 & 33 & 49 & 18 \\
2 & 34 & 49 & 17 \\
3 & 27 & 56 & 17 \\
4 & 26 & 44 & 30 \\
5 & 35 & 45 & 20 \\
6 & 44 & 35 & 21 \\
7 & 36 & 40 & 20 \\
8 & 35 & 46 & 20 \\
9 & 42 & 35 & 23 \\
10 & 18 & 62 & 20 \\
11 & 40 & 47 & 13 \\
12 & 15 & 68 & 17 \\
13 & 50 & 36 & 14 \\
14 & 22 & 61 & 17 \\
15 & 23 & 59 & 18 \\
16 & 39 & 43 & 18 \\
17 & 44 & 40 & 16 \\
18 & 25 & 56 & 19 \\
\hline Mean & 33 & 48 & 19 \\
S.D. & 9.4 & 9.9 & 3.7
\end{tabular}

It is apparent from Table I that: 1) The percentage of words categorized as primarily visual ranges from 15 - 50 (37 - 124 words). The kinesthetic percentage range is $35-68$ (86 - 143 words); and the auditory range is $13-30$ ( $32-74$ words). Ss. do not differ greatly in the percentage of words that are categorized as primarily auditory, S.D. $=3.7$, but have greater and approximately equal disagreement upon the number of words categorized as primarily kinesthetic, S.D. $=9.9$, and visual, S.D. $=9.4$.

If a "client" presented these 18 "therapists" with these 247 predicates, then 18 different profiles would result. These 18 "therapist" profiles can be sorted into three types, illustrated by Figure 2. 


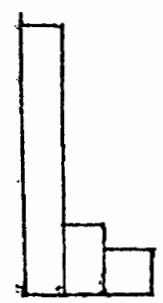

TYPE I

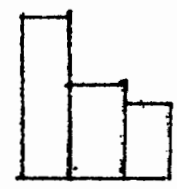

TYPE II

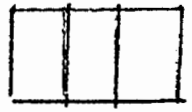

TYPE III

Eigure 2. Schematic for Typing Subjects by the Percentage of words categorized in each modality.

Table II presents the percentage of $\underline{S}$. by type and modality.

TABLE II

PERCENT OF SUBJECTS BY TYPE AND MODALITY

TYPE I

HIGH
TYPE II

STRONGLY

RULE : $\geq 50 \%$ of words $\geq 40 \%$ of words categorized in categorized in one modality one modality and $\geq 15 \%$ difference between modalities
TYPE III

UNDIFFERENTIATED $\mathrm{V}-\mathrm{K}$ $\leq 15 \%$ difference between
$\bar{V}$ and $K$ modalities

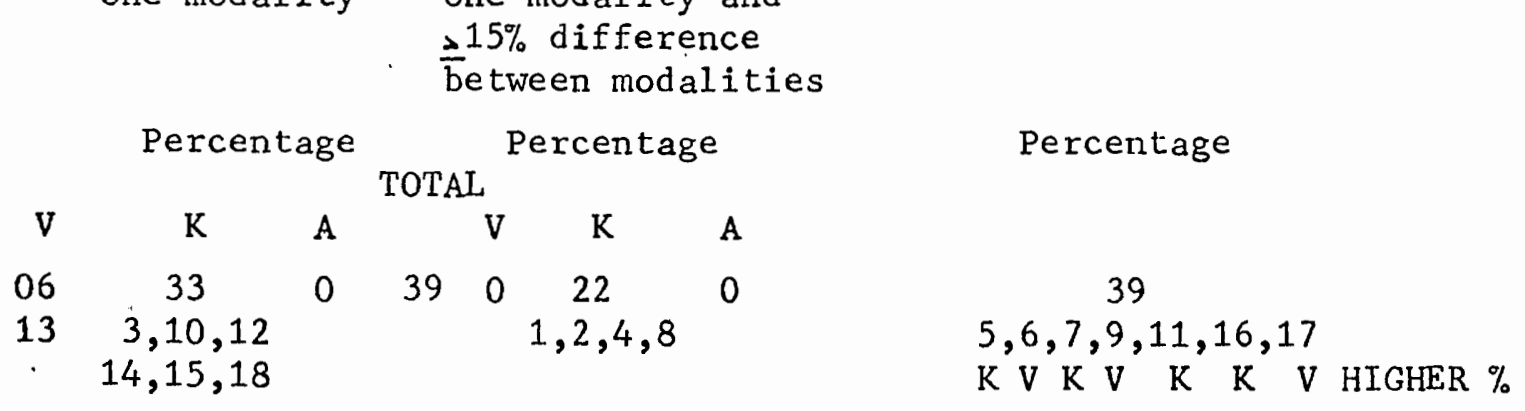

Ss. then have differing styles. for categorizing words. The next questions that one can ask are: '1) How do these styles differ, and 2) What might account for these differences? 
Returning to Table $I$, one can see that the percentage of auditory words does not fluctuate greatly over $\underline{S} s$, but there appears to be an inverse relation between words scored as primarily visual, and primarily kinesthetic. To test this out each $\underline{S}$.'s visual percentage (VISALL) was plotted against their auditory percentage (AUDALL) and their kinesthetic percentage (KINALL) similarly plotted against AUDALL; see Appendix E. A Pearson's $r$ was calculated for each of these: VISALL - AUDALL $=.16$, KINALI - AUDALL $=-.22$. VISALL - KINALL were plotted against each other and a correlation calculated or $r=-.97$. These coorelations suggest that the auditory modality is independent of both the visual and kinesthetic and that the visual and kinesthetic modalities have an almost perfect inverse relationship.

H2: Subjects' judgments of each other's sensory profile will be biased in the direction of their own profile.

There are a number of possibilities as to what might account for these differences in style. The first is that since this 247 word 1 ist contains between 7 and 15 of each $\underline{S}$.'s own words, that this might in some way affect a $\underline{S}$.'s overall percentage categorization of words. Percentage scores were calculated for each S.'s categorization of his/ her own words and for each other $\underline{s}$.'s words, as well as standard deviations (visual and kinesthetic) for each $\underline{S}$.'s words; see Appendix F. The two $\underline{S}$ s. whose words were categorized as most variable by all other Ss. were pulled from the test 1 ist $S$ 非 and $S$ 非17. These words because they were scored as most variable might give a clearer indication of a S.'s profile: This new test list consisted of an independent sample 
of 30 words. A Ss.'s categorization of these words is labeled VIS30 and KIN30. To test whether this was a representative sample, a Pearson's $x$ was calculated for VIS30 and KIN30 with the remaining 217 words. Pearson's r VIS30 - VIS217 $=.88$, significant at the .0005 level; and KIN30 - KIN217 =.93, significant at the .0005 level. These correlations suggest: 1) The 30 words are a representative sample, and 2) Variations in scoring of the 247 words cannot be accounted for by the presence of a $\underline{S}$.'s own words.

A $\underline{S}$.'s categorization of his own words might however indicate how he would categorize other people's words. Each $\underline{S}$.'s visual score of his own words (VISOWN) and kinesthetic score (KINOWN) were plotted against his/her scoring of all words (VISALL and KINALL); see Appendix G. Correlations for VISOWN - VISALL $=.54$, significant at the .01 leve1, and KINOWN - KINALL $=.40$, significant at the .05 level. There is then a high correlation between how visual a $\underline{S}$. sees his own words and how he sees others' words and how kinesthetic he perceives his own words and others' words. This would suggest that an $\underline{S}$.' $s$ categorization of all $\underline{\mathrm{S}} \cdot$ 's words are biased in the direction of his categorization of his own words. Table III presents scores by $\underline{\text { S }}$. on 30 words and 217 words. Table IV presents scores by $\underline{\text { S }}$. on own words. 
TABLE III

SCORES BY SUBJECT ON 30 WORDS AND 217 WORDS

30 Words

217 Words

$\begin{array}{rcccccc}\text { Subject } & \begin{array}{c}\text { Visual } \\ \text { Per. }\end{array} & \begin{array}{c}\text { Kinesthetic } \\ \text { Per }\end{array} & \begin{array}{c}\text { Auditory } \\ \text { Per }\end{array} & \begin{array}{c}\text { Visual } \\ \text { Per. }\end{array} & \begin{array}{c}\text { Kinesthetic } \\ \text { Per }\end{array} & \begin{array}{c}\text { Auditory } \\ \text { Per. }\end{array} \\ 2 & 33 & 57 & 10 & 31 & 49 & 20 \\ 3 & 10 & 76 & 14 & 29 & 53 & 18 \\ 4 & 24 & 56 & 20 & 27 & 41 & 32 \\ 5 & 34 & 53 & 13 & 36 & 44 & 20 \\ 6 & 50 & 40 & 10 & 44 & 34 & 22 \\ 7 & 34 & 54 & 12 & 36 & 43 & 21 \\ 8 & 33 & 47 & 20 & 35 & 46 & 19 \\ 9 & 36 & 44 & 20 & 42 & 34 & 21 \\ 10 & 04 & 76 & 20 & 20 & 61 & 19 \\ 11 & 40 & 46 & 14 & 36 & 47 & 17 \\ 12 & 0 & 87 & 13 & 17 & 66 & 23 \\ 13 & 50 & 37 & 13 & 50 & 37 & 13 \\ 14 & 23 & 66 & 11 & 22 & 60 & 18 \\ 15 & 10 & 79 & 11 & 24 & 57 & 19 \\ 16 & 38 & 48 & 14 & 29 & 42 & 19 \\ 18 & 16 & 70 & 14 & 26 & 55 & 19\end{array}$

TABLE IV

PERCENTAGE SCORES BY SUBJECT ON OWN WORDS

$\begin{array}{cccc}\text { Subject } & \text { Visual } \% & \text { Kinesthetic } \% & \text { Auditory } \% \\ 1 & 27 & 60 & 15 \\ 2 & 40 & 13 & 47 \\ 3 & 33 & 53 & 13 \\ 4 & 47 & 33 & 20 \\ 5 & 20 & 33 & 47 \\ 6 & 29 & 71 & 0 \\ 7 & 18 & 45 & 36 \\ 8 & 14 & 57 & 29 \\ 9 & 29 & 43 & 29 \\ 10 & 07 & 73 & 20 \\ 11 & 40 & 30 & 30 \\ 12 & 17 & 75 & 08 \\ 13 & 67 & 33 & 0 \\ 14 & 33 & 53 & 13 \\ 15 & 36 & 50 & 14 \\ 16 & 53 & 40 & 07 \\ 17 & 38 & 54 & 08 \\ 18 & 07 & 86 & 07\end{array}$


A further question that $c$ an be asked of these data is "To what extent is an $\underline{S}$. perceived by others similarly to the way in which he perceives himself?" For each $\underline{S}$. a percentage score was calculated to ascertain how visual and how kinesthetic other $\underline{S}$. categorized each other $\underline{S}$.'s own words = VISOTR and KINOTR. These percentage scores were correlated with VISOWN, VIS30, VISALL, KINOWN, KIN30, and KINALL, and are presented in Table $V$.

\section{TABLE $V$}

CORRELATIONS OF VISOTR AND KINOTR WITH VISONN, VIS30, VISALL, KINOWN, KIN30, KINALL, KINOTR AND VISOTR.

VISOWN VIS30 VISALL KINOWN KIN30 KINALL KINOTR VISOTR

\begin{tabular}{|c|c|c|c|c|c|c|c|c|}
\hline VISOTR & .50 & -.30 & -.25 & -.19 & .31 & -- & -.47 & -- \\
\hline KINOTR & -.33 & .02 & -0 & .72 & -.05 & -.09 & -- & -.47 \\
\hline
\end{tabular}

Graphs of VISOWN - VISOTR, KINOWN - KINOTR, VISOTR - VISALL, KINOTR - KINALL, VISOWN - VIS30, KINOWN - KIN30 appear in Appendix $H$. These data suggest: 1) A high correlation between how visual a $\underline{S}$. perceives his own words and how visual these words are perceived by others: " $r=.53$, significant at the .01 level. This correlation is for the $\frac{\dot{s}}{\dot{y}}$ 's own words (maximum 15). 2) As the sample of words to be categorized increases ( 30 or 247 words) agreement between $\underline{S}$. decreases,!VISOTR - VIS30 $=.30$, VISOTR - VISALL $=.25$. 3) A high correlation exists between KINOTR - KINOWN $=.72$, significant at the .0005 level, and 4) A greatly decreased correlation with increased sample size; KINOTR - KIN30 $=.05$, KINOTR - KINALL $=-.09$. 
H3: Sex will bias sensory profiles.

Sex|was correlated with VISOWN, VISOTR, VIS30, KINOWN, KINOTR, and KIN30, No significant correlation was found between sex of $\underline{\text { S. }}$ and any of the above variables. 
CHAPTER IV

\section{DISCUSSION}

This research can be seen as an exploratory study into an area that is complex and generally inhospitable to rigorous research. It is an area in which the researcher comes face to face with... a mirror. It is impossible to "objectively" define visual, kinesthetic and auditory. Their definitions are dependent upon the predominance of these characteristics in a population, as defined by the population.

If one conceptualizes visual, kindesthetic and auditory ( $\mathrm{V}, \mathrm{K}$, and
A) as three intersecting planes, then each $\underline{S}$. or population will have a distinct point of origin, defined by their profile. This "point of origin" is the degree to which they experience the world as visual, kinesthetic and auditory. It is their perspective. In this model, each $\underline{S}$. understands the meaning of visual, kinesthetic and auditory, analogous to up-down, left-right and forward-backward. Each $\underline{S}$. can then judge how "near" or how "far" a word is in relation to his origin. Grinder and Bandler's theory for mapping representational systems suggests that one can objectively type an individual by categorizing his predicates. For this to be reliable, an individual's origin should not affect his categorization of words. This is somewhat paradoxical: why should an individual's sensory profile influence his choice of words and not his judgment of words? 
A . may indeed be able to be categorized by his use of predicates, as to having a Most Highly Valued Representational System. However, how he is categorized will be influenced by the M.H.V.R.S. of the judge. There is then an error factor. It is probable, given the above model, that the farther the distance of a $\underline{S}$.' $s$ origin on a $V, K$, or $A$ vector the greater the number of words that will be categorized as being of that modality.

If a $\underline{S}$. is highly kinesthetic, he will categorize more words in that modality than a $\underline{S}$. who is highly visual. This then is the mirror image of categorizing a $\underline{S}$. by his use of predicates; it is categorizing a judge by the style in which he judges. This may then be a more accurate way of determining a sensory profile and is essentially a projective test.

If an "objectively" highly visual client goes to see a highly kinesthetic therapist, the following might occur. The client produces 100 predicates, 75 of which he considers to be visual, and 25 of which he considers to be kinesthetic. The therapist correctly classifies all of the client's kinesthetic predicates as kinesthetic and $33 \%$ of his visual predicates as kinesthetic. The client is now understood by the therapist as being equally visual and kinesthetic. of course the client will produce more than 100 predicates. The greater the number of words the greater the chances that they will be reinterpreted, biased in the direction of the therapist's own M.H.V.R.S.

Kel1y's (1955, p. 58) commonality corollary states: 
To the extent that one person employs a construction of experience which is similar to that employed by another, his processes are psychologically similar to those of the other person.

Simply stated this corollary suggests that while individuals may have had differing experiences, they may have arrived at similar ways of understanding the world; i.e., they may have similar world images. Kelly continues with his sociality corollary:

To the extent that one person construes the construction processes of another, he may play a role in the social processes involving the other person.

These two corollaries taken together state that although we may have developed similar constructs in different ways, to the extent that mine are similar to yours, we can understand each other.

From this it follows that a judgment of a $\underline{S}$. 's sensory profile will be accurate (with regard to how a $\underline{S}$. judges himself) to the extent to which the judge's profile is similar to that of the $\underline{S}$. being judged. One example taken from these data illustrates this pattern: S. 非12 judges her own words as $\mathrm{V}=.17, \mathrm{~K}=.75$ and $\mathrm{A}=.08$. She judges $S_{-}$非13's words as $V=.20, K=.60, A=.20$. $\underline{S}$. 非13 judges his own words as $\mathrm{V}=.67, \mathrm{~K}=.33$ and judges $\underline{\mathrm{S}}$. 非12's words as $\mathrm{V}=.50$, $\mathrm{K}=.42$ and $\mathrm{A}=.08$. Each of these $\underline{S}$. judges the other similarly to

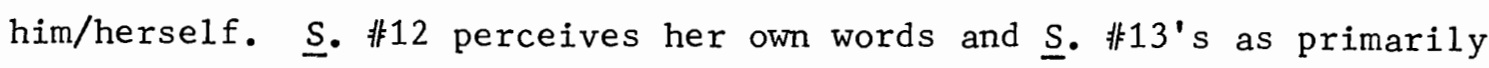
kinesthetic, although $\underline{S}$. \#13 perceives himself as primarily visual. S. \#13 sees his own words and $\underline{S}$. 非12's as primarily visual although S. 非12 perceives herself as kinesthetic.

\section{Sererar factors may have influenced the kind and variability of}

these results. 1) There was a small, culturally homogeneous sample. It is quite possible that the selection and sorting of words is 
influenced by culture and socioeconomic backgrounds. This may account for the small percentage of auditory words, the high $\underline{S}$. agreement regarding these words, and the large number of kinesthetic words. A more heterogeneous sample may produce even greater variability in the scoring of these words. It is generally reported that we live in a highly visual society. The large number of words scored as kinesthetic is a surprise. One wonders then whether the reporting is done by highly visual people. 2) The choice of the words "event," "details" and "describe" in the instructions. These words were selected to be vague; a choice of other words may have produced different results. 3) The content of the events described may have influenced the choice of words. 4) The test list consisted of words taken out of context. It is clear that meaning is context-dependent. It is quite possible that judgments of context would be biased, to the same degree as judgments of single words. 
CHAPTER V

CONCLUSIONS AND SUGGESTIONS FOR FURTHER RESEARCH

\section{Conclusion}

Several possible conclusions are suggested by these data:

1) Each individual has a sensory profile. This profile can be accessed via his judgments of words.

2) An individual's judgments of another's words will be biased in the direction of his judgments of his own words.

3) As the number of words judged increases the agreement between judges decreases.

4) Sex does not influence in any systematic way judgments of words. Bandler and Grinder (1976) have presented an elegant and understandable system for mapping an individual's sensory profile. Unfortunately, these data suggest that it is too simple. It does not take into account the map of the mapper.

\section{Limitations of the Study}

This study was intentionally limited in a number of ways: 1) The words "saw," "felt," and "heard" were used in the initial instructions. These words were chosen because they are the verbs that Grinder and Bandler use to delineate their categories and because they are words that are often used in the context of therapy. It is important to Mite that within the context of therapy a client (and of ten the 
therapist) is asked to speak and to act in ways that are of ten different from his routine behavior. 2) The instructions were terse and interactions with the $\underline{E}$. were kept to a minimum. It is quite possible that one selects different words in different situations and with different people. A mutual shaping occurs. Therapists may shape clients and clients may shape their therapists. The "Rosenthal effect" gives evidence for this type of interaction.

\section{Implications for Therapy}

Mapping a client's sensory profile can be an invaluable tool for a therapist. Bandler and Grinder (1976); Watzlawick (1978); and Gordon (1978) have demonstrated that accurately detecting the client's representational system can have a powerful impact upon the course of therapy. The question remains as to how accurate and reliable this mapping is. Bandler and Grinder (1976, p. 7) state that the words "clear," "vivid," and "saw" are words to be categorized as visual. This researcher found the following categorizations for these words:

Visual $\% \quad$ Kinesthetic $\% \quad$ Auditory $\%$

$\begin{array}{lrrr}\text { clear } & 72 & 28 & 0 \\ \text { vivid } & 88 & 22 & 0 \\ \text { saw } & 83 & 11 & .05\end{array}$

These percentages are for words that Bandler and Grinder presented as exemplary of the visual modality. If such discrepancies can be found for words that are so "obviously" of one modality, then as words are less well defined (i.e., loaded in one modality) the reliability as to how they are to be judged must decrease. Some examples are 
"laughed" and "jump." One would expect the former to be auditory and the latter kinesthetic. Percentages for these words were:

$$
\text { Visual } \% \quad \text { Kinesthetic } \% \quad \text { Auditory } \%
$$

$\begin{array}{lrrr}\text { laughed } & .05 & .33 & .61 \\ \text { jump } & .44 & .66 & 0\end{array}$

Other words such as "practiced" and "bubbling" showed approximately equal loading in all modalities.

$$
\text { Visual } \% \quad \text { Kinesthetic } \% \quad \text { Auditory } \%
$$

$\begin{array}{llll}\text { practiced } & .33 & .44 & .22 \\ \text { bubbling } & .33 & .44 & .22\end{array}$

From this standpoint it becomes even more critical that the therapist know himself, his biases, his perceptions of the world and how they may influence his perceptions of others. If I am highly visual, I can be "on the lookout" for ways in which I "see" utterances by others "showing" evidence of a visual representational system. First, however, I must ascertain what is my predominant modality. The following are several suggestions as to how this might be achieved reliably.

\section{Suggestions for Further Research}

1) A number of words (7) appeared in the list which were categorized by Ss. as equal in all three modalities. These words could be considered as a litmus test. These "modality ambiguous" words might be scored as visual by visual people, kinesthetic by kinesthetic people, etc. See Appendix I for scoring of words by modality. 2) A projective test, similar to the test list, could be developed. This would use a much larger $N$ and would be tested against many differing S. populations. 3) In a workshop in Portland, Oregon, 
October, 1978, Frank Pucelik of Meta Training Associates, San Diego, California, presented the following table of Most Highly Valued Representational System correlates:

\section{TABLE VI}

MOST HIGHLY VALUED REPRESENTATIONAL SYSTEM CORRELATES

$\begin{array}{lllll} & \text { V } & \text { K } & \text { A Tonal } & \text { A Digital } \\ \text { Predicate } & \text { Picture } & \text { Touch } & \text { Sound } & \text { Understand } \\ \text { Distance } & \text { Far } & \text { Close } & & \text { Far } \\ \text { Eye Elevation } & \text { Above } & \text { Below } & & \text { Above } \\ \text { Posture } & \text { Upright } & \text { Bent } & \text { Straight } & \text { Rigid - Up } \\ \text { Satir Categories } & \text { Blamer } & \text { Placater } & \text { Super-Reasonable } & \\ \text { Rules } & \text { Look to } & & \text { Do not look } & \text { No contact } \\ & \text { listen } & & \text { to listen } & \\ \text { Tonality } & \text { Clear-Loud } & \text { Airy } & \text { Rhythmic } & \text { Monotone } \\ & \text { Fast } & \text { Soft-Low } & & \\ \text { Breathing } & \text { High } & \text { Low } & \text { All-Over } & \text { Restricted }\end{array}$

Predicate: Refers to the modality the words connote. Distance: Refers to the proximity of client to the therapist. Eye Elevation: Refers to the positioning of the client's eyes, either above or below the therapist's eyes.

Posture: Refers to how the client is sitting.

Satir Category: Refers to a system of character typing developed by Virginia Satir (1972). She types people into Blamers, P1acaters, Distractors, and Computers. Super-Reasonable is analogous here to Satir's Computer type.

Tonality: Refers to the sound of the client's voice. 
Breathing: Refers to the location and expansion of the chest.

It is possible that using all these measures a more reliable determination of $\underline{S}$.'s sensory profiles could be achieved. 
List of References

Amarel, S. 1968. On representations of problems of reasoning about action. In Machine intelligence III, ed. D. Mitchie, pp. 140190. New York: American Elsevier.

Anderson, J., and Bower, G. 1974. Human associative memory. New York: Wiley.

Anderson, N. 1974. Algebraic models in perception. In Handbouk of perception, vol. II, eds. E. Carterelte and M. Fricdman, pp. 215300. New York: Academic Press.

Aziz, B. 1978. Maps and the mind. Human Nature 8: 50-51.

Bach-y-Rita, P. 1972. Brain mechanisms in sensory substitution. New York: Academic Press.

Bandler, J., and Grinder, R. 1975. The structure of rnagic. Palo Alto: Science and Behavior Books.

Bannister, D., and Mair, S. eds. 1968. The evaluation of personal constructs. New York: Academic Press.

Bateson, G. 1972. Steps to an ecology of mind. New York: Ballantine. - 1979. Mind and nature, a necessary unity. New York: E. P. Dutton.

Békésy, G. von 1959. Similarities between hearing and skin sensations. Psych. Rev. 66:1-22.

Bever, T. 1970. The cognitive basis of linguistic structures. In Cognition and the development of language. ed. J. Hayes, pp. 160-190. New York: Wiley.

Blank, M., and Kling, S. 1970. Dimensional learning across sensory modalities in nursery school children. J. of Experimental Psychology $92166-73$.

Bridgman, P. 1959. The way things are. Cambridge: Harvard University Press.

Clark, H., Carpenter, P., and Just, M. 1973. On the meeting of semantics and perception. In W. G. Chase, ed. Visual Information Processing. New York: Academic Press.

Eccles, J., ed. 1966. Brain and conscious experience. New York: Springer-Veriag. 
Erickson, M., Rossi, E., and Rossi, S. 1976. Hypnotic realities. New York: Irvington.

Fagan, J., and Shepherd, I. 1970. Gestalt therapy now. New York: Harper and Row.

Galin, D. 1974. Implications for Psychiatry of Left and Right Cerebral Specialization. Archives of General Psychiatry 31: 572-83.

Gellhorn, E. 1964. Motion and emotion; the role of proprioception in the physiology and pathology of emotions. Psych. Rev. 71: 457-72.

Geschwind, N. 1967. Studies of hemispheric connection. In Brain mechanisms and underlying speech and language. C. Milikan and F. Darley, eds. New York: Grune and Stratton.

Gibson, E. 1969. Principles of perceptual learning and development. New York: Appleton Century Crofts.

Gordon, D. 1978. Therapeutic metaphors. Cupertino, CA: Meta Publications.

Grinder, J., and Bandler, R. 1976. The structure of magic, vol. II. Palo Alto: Science and Behavior Books.

Grinder, J., Delozier, J., and Bandler, R. 1977. Patterns of the hypnotic techniques of Milton H. Erickson, M.D., vol. 2 . Cupertino, CA: Meta Publications.

Haley, J. 1976. Problem solving therapy. New York: Harper-Colophon.

Hayes, W. 1973. Statistics for the social sciences. New York: Holt, Rinehart and Winston.

Jaynes, J. 1977. The origin of consciousness in the breakdown of the bicameral mind. New York: Houghton Mifflin.

Jordon, S. 1964. The deaf-blind: a clarification. perception and Motor Skills 18: 503-04.

Kelly, G. 1955. The psychology of personal constructs. New York: W. H. Norton.

Mainwaring, J. 1932. Kinesthetic factors in the recall of musical experiences. British J. of Psychology 23: 284-307.

Masterton, R. and Berkley, M. 1974. Brain function: changing ideas on the role of sensory motor, and association cortex in behavior. Annual Review of Psychology 25: 277-312. 
Melzack, R. 1973. The puzzle of pain. New York: Basic Books. Metzner, R. 1971. Maps of consciousness. New York: Holt, pp. 9-15.

Millar, S. 1972. The development of visual and kinesthetic judgments of distance. British J. of Psychology 9 (3) 169-176.

Miller, G., Galanter, E., and Pribram, K. 1960. Plans and the Structure of Behavior. New York: Holt, pp. 20-50.

Miller, G., Johnson-Laird, P. 1976. Language and Perception. Cambridge: Harvard University Press.

Milne, A. 1969. A developmental study of touch and vision: form learning and cross-modal transfer. Dissertation Abstracts. 29 (76): 2656.

Milner, P. 1970. Physiological psychology. New York: Holt.

Moeser, S. and Bregman, A. 1972. Imagery and language. Presented paper. Simon Fraser U., Burnaby, B.C.

Polanyi, M. 1958. Personal knowledge. Chicago: University of Chicago Press.

Polster, E. and Polster, M. 1973. Gestalt therapy integrated. New York: Random House.

Pribram, K. 1971. Languages of the brain. Englewood Cliffs, N.J.: Prentice Hall.

Pucelik, F. 1978. Representational system correlates. Workshop. Sheraton Inn, Portland Airport, Portland, Oregon.

Reusch, J. and Bateson, G. 1951. Communication: the social matrix of psychiatry. New York: W. H. Norton.

Rudel, R. and Teuber, H. 1964. Cross-modal transfer of shape discrimination by children. Neuropsychologia 2: 1-8.

Ryle, G. 1949. The concept of mind. New York: Barnes \& Noble.

Sapir, E. 19.56. Culture, language and personality. D. Mandelbaum, ed. Berkley: U. of California Press.

Satir, V. 1967. Conjoint family therapy. Palo Alto: Science and Behavior Books. Books.

1972. Peoplemaking. Palo Alto: Science and Behavior 
Spencer, D. 1970. Life span changes in intersensory and intrasensory integration functioning. Dissertation Abstracts. 30: 4402.

Sperry, R. and Gazzaniga, M. 1967. Language following surgical disconnection of the hemispheres. In F. Darley, ed. Brain Mechanisms Underlying Speech and Language. New York: Grune and stratton.

Treisman, A. 1969. Strategies and models of selective attention. Psych. Rev. 76 (3): 282-299.

Turbayne, C. 1962. The Myth of Metaphor. New Haven: Yale University Press.

Watzlawick, P. 1978. The language of change. New York: Basic Books.

Whorf, B. 1956. Language, Thought and Reality. J. Carroll, ed. Cambridge: M.I.T. Press. 
TEST LIST

V A K

1. around

2. deformed

3. support

4. shove

5. saw

6. 1isten

7. felt

8. believe

9 . describe

10.

11. anxious

12. end

13. tell

14. distressed

15. rel axed

16. aware

17. saw

18. saying

19. in

20. applied

21. Iisten

22. beautiful

23. saw

24. told

25. swatting

26. talked

27. heard

28. coming in

29. healing

30. found

31. dark

32. explain

33. part

34. attacked

35. felt

36. hazy

37. noticed

38 .

39. unconnected

40.

41. heard

42. aware

43.

44 .

45. eating
46. changing

47. pick up

48. down

49. ordered

50. miserable

51. cool

52. within

53. passed by

54. stared

55. wordless

56. yelling

57. know

58. around

59. out

60. beginning

61. carried

62. comfortable

63. arrived

64. Sound

65. practicing

66. Iong

67. frightened

68. wandered

69. sitting

70. received

71. 1 ay

72. distracted

73. eerie

74. got out

75. offered

76. felt

77. jump

78. deal with

79. talking over

80. impressed

81. sensing

82. connected

83. paying attention

84. felt

85. around

86. swearing

87. back \& forth

88. screaming

89. magical

90. walked
V A K

$\mathrm{V}|\mathrm{A}| \mathrm{K}$

91. get together

92.

93. getting into

94. brightest

95. tone

96. loaded

97.

98. excited

99. shock

100. bother

101. safe

102. bl ankly

103. shock

104. picking

105. heard

106. doing

107. came to be

108. love

109. playing

110. angry

111. sleepy

112. say

113. exchanged

114. felt

115. knowing

116. describe

117. chase

118. get to

119. give

120. seeing

121. ask

122. upcoming

123. unsettling

124. disconcerting

125. taking time

126. movement

127. get away

128. happy

129. turned out

130 .

131. I aughed

132. overconfident

133. distracted

134. harder

135. received 
V A K

V A K

\begin{tabular}{ll|l}
$V$ & $A$ & $K$
\end{tabular}

136. watching

137.

138. standing

139. vivid

140 .

141 .

142. pushed

143.

144. irritated

145. saw

146. reacled

147. angiry

148.

149 .

15(). crushed

151. see

152. rumbled

153. totalled

154. selecting

155. all over

156. vivid

157. polite

158. crossing

159. kick

160. sprayed

161. recomnended

162. empty

163. slowly

164 .

165. cone up

166.

167. Listened

168. observing

169.

170. subtle

171. finished

172. strange

173.

174. he ard

175. covered

176. angry

177 .

178. easy

179. stimulating

180. chose

181. bad

182. stand up

183. get in

184. see

18.5. care

186. greenest

187. powerless

188.

189.

190.

191. come get

192. walked

193 .

194.

195. called

196. pastel

197. hear

198.

199. hard

200. irrilated

201. Exhausted

202. whizzed

20) 3 .

2014. heard

205 .

206. heard

207 . woke up

208. cursing

209. felt

210 .

211. over

212. gray

213. painful

214. dirty.

215. please

216.

217.

218. hearing

219.

220. moved

221. movement

222. talking

223. saw

224. sl oppy

225. weightless

226. dirty

227. curious

228. pressure

229. gratified

230 .

231. coaxing
232 .

233. roaring

234.

235. incongruous

236. took

$23 \%$. embarrassed

238.

239. humid

24(). at that point

241. reeling

242. called

243.

244 .

245 .

246 .

247. picked up

248 .

249. dovilish

25). noaring

251. talking

252 .

253.

254.

255. turned out

256 . wandered

257. sticks

258. yelling

259 .

260 .

261 .

262. allxious

263. looking

264. printed

165. end

266 .

267. looking

268 . observing

269. frozen

270 . went

271. f inished

272. bizarre

273. saw

274. entered

275. saw

276. talking

277. understand

278. at tended

279. felt. 
$\mathrm{V} A \mathrm{~K}$

280. pulled up 281. cut

282. dealing

283. hike

284. buzzing

285 .

286. going through

287. feel

288. clear

289. roaring

290 .

291. Iittle

292. talked

293.

294. divided 295. hot

296. patient

297. paid

298. ask

299. bubbling

300. weighed 
1. around

2. deformed

3. support

4. shove

5. s aw

6. listen

7. felt

8. believe

9. describe

11. anxious

12. end

13. tell

14. distressed

15. rel axed

16. aware

17. saw

18. saying

19. in

20. applied

21. listen

22. beautiful

23. saw

24. told

25. swatting

26. talked

27. heard

28. coming in

29. healing

30. found

31. dark

32. explain

33. part

34. attacked

35. felt

36. hazy

37. noticed

39. unconnected

41. heard

42. aware

45. eating

46. changing

47. pick up

48. down

49. ordered

50. miserable

51. cool

52. within

53. passed by

54. stared
55. wordless

56. yelling

57. know

58. around

59. out

60. beginning

61. carried

62. comfortable

63. arrived

64. sound

65. practicing

66. long

67. frightened

68. wandered

69. sitting

70. received

71. 1 ay

72. distracted

73. eerie

74. got out

75. offered

76. felt

77. jump

78. deal with

79. talking over

80. impressed

81. sensing

82. connected

83. paying attention

84. felt

85. around

86. swearing

87. back \& forth

88. screaming.

89. magical

90. walked

91. get together

93. getting into

94. brightest

95. tone

96. loaded

98. excited

99. shock

100. bother

101. safe

102. blankly

103. shock

104. picking

105. heard
106. doing

107. came to be

108. love

109. playing

110. angry

111. sleepy

112. say

113. exchanged

114. felt

115. knowing

116. describe

117. chase

118. get to

119. give

120. seeing

121. ask

122. upcoming

123. unsett 1 ing

124. disconcerting

125. taking time

126. movement

127. get away

128. happy

129. turned out

131. laughed

132. overconfident

133. distracted

134. harder

135. received

136. watching

138. standing

139. vivid

142. pushed

144. irritated

145. saw

146. reacted

147. angry

150. crushed

151. see

152. rumbled

153. totalled

154. selecting

155. all over

156. vivid

157. polite

158. crossing

159. kick

160. sprayed

161. recommended 
162. empty

163. slowly

165. come up

167. lis tened

168. observing

170. subtle

171. finished

172. strange

174. heard

175. covered

176. angry

178. easy

179. stimulating

180. chose

181. bad

182. stand up

183. get in

184. see

185. care

186. greenest

187. powerless

191. come get

192. walked

195. called

196. pastel

197. hear

199. hard

200. irritated

201. exhausted

202. whizzed

204. heard

206. he ard

207. woke up

208. cursing

209. felt

211. over

212. gray

213. painful

214. dirty

215. please

218. hearing

220. move

221. movement

222. talking

223. saw

224. sloppy

225. weightless

226. dirty

227. curious

228. pressure

229. gratified

231. coaxing

233. roaring
235. incongruous

236. took

237. embarrassed

239. humid

240. at that point

241. feeling

242. called

247. picked up

249. devilish

250. nearing

251. talking

255. turned out

256. wandered

257. sticks

258. yelling

262. anxious

263. looking

264. printed

265. end

267. looking

268. observing

269. frozen

270. went

271. finished

272. bizarre

273. saw

274. entered

275. saw

276. talking

277. understand

278. at tended

279. felt

280. pulled up

281. cut

282. dealing

283. hike

284. buzzing

286. going through

287. feel

288. clear

289. roaring

291. little

292. talked

294. divided

295. hot

296. patient

297. paid

298. ask

299. bubbling

300. weighed 
LIST OF DUPLICATE AND SIMTI,AR WORDS

\begin{tabular}{|c|c|}
\hline around & $1,58,85$ \\
\hline s aw & $5,17,23,145,223,273,275$ \\
\hline felt & $7,35,76,84,114,209,279 ; 241$ feeling, 287 feel \\
\hline describe & 9,116 \\
\hline anxious & 11,262 \\
\hline end & 12,265 \\
\hline aware & 16,42 \\
\hline talked & 26,292 \\
\hline heard & $27,41,105,174,204,206,218 ; 197$ hear \\
\hline unconnected & $39 ; 82$ connected \\
\hline yelling & 56,258 \\
\hline know & 57; 115 knowing \\
\hline wandered & 68,256 \\
\hline distracted & 72,133 \\
\hline deal with & $78 ; 282$ dealing \\
\hline wal ked & 90,192 \\
\hline getting into & $93 ; 118$ get to \\
\hline shock & 99,103 \\
\hline angry & $110,147,176$ \\
\hline seeing & $120 ; 184$ see \\
\hline ask & 121,298 \\
\hline harder & $134 ; 199$ hard \\
\hline irritated & 144,200 \\
\hline see & 151,184 \\
\hline observing & 168,268 \\
\hline finished & 171,271 \\
\hline called & 195,242 \\
\hline dirty & 214,226 \\
\hline talking & $222,251,276$ \\
\hline looking & 263,267 \\
\hline
\end{tabular}


APPENDIX D

PRIMARY AND SECONUARY RF.SPONSES

FOR ALL WORDS BY SUBJF.CTS

Oala $r::$ sunje: 1

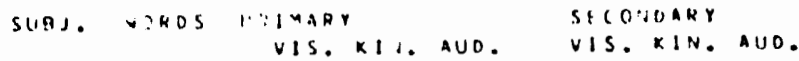

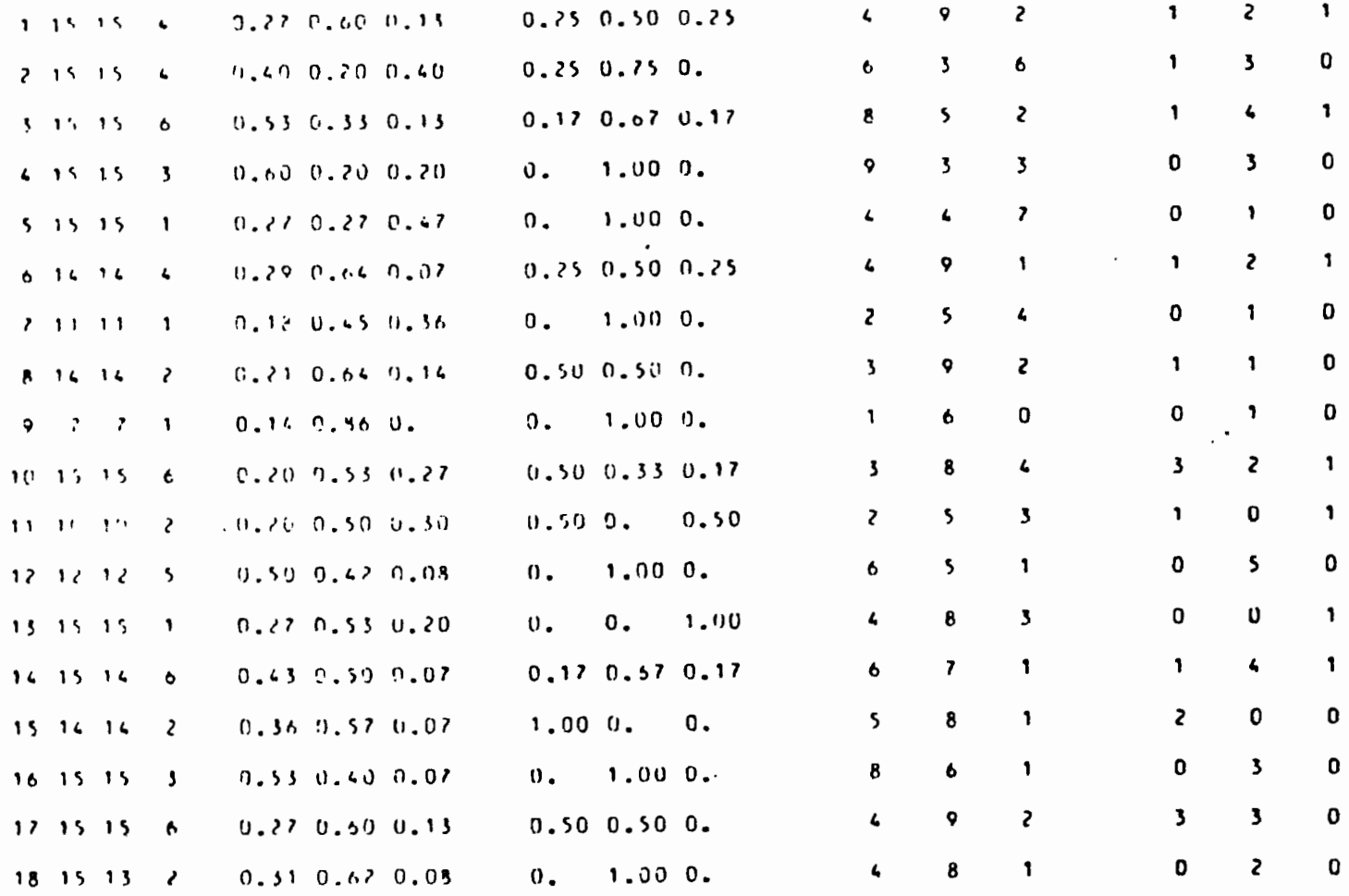




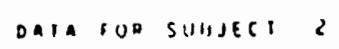




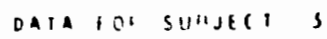

SUHJ. GOODS HEIAARY SECOURAAY

VIS. I. AUD. VIS. KII:. AUD.

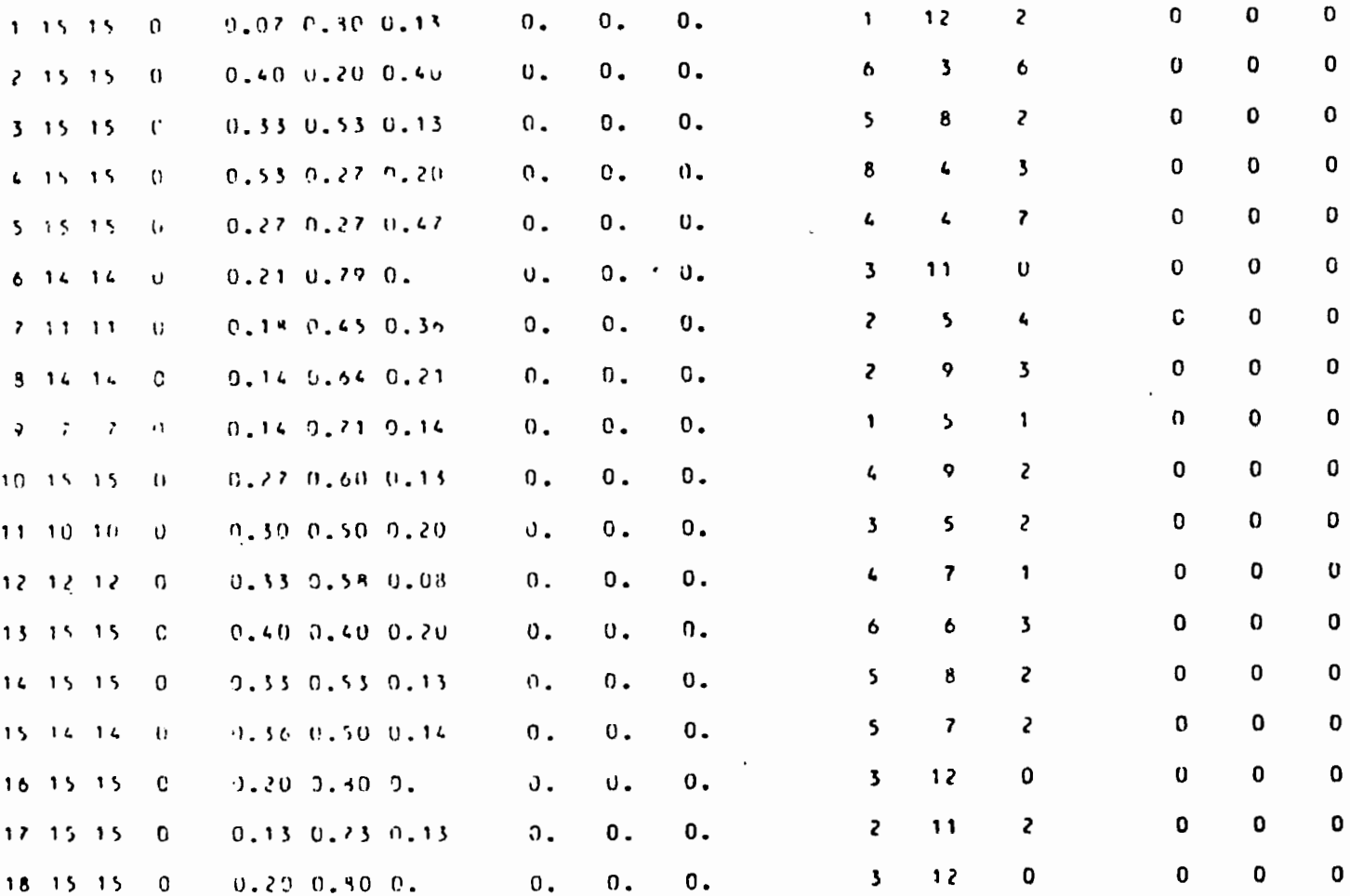




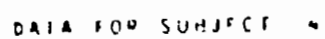

SUAJ. WHOS ARIMARY SECOHDARY

VIj. KIV. AUD. JIJ.KIH. MUO.

\begin{tabular}{|c|c|c|c|c|c|c|c|c|c|c|c|c|c|c|}
\hline 1 & 15 & 15 & 0 & 10.0 & 7.33 & 0.27 & ग. & 0 & 0. & 6 & 5 & $\iota$ & 0 & 0 \\
\hline 2 & 15 & 15 & 1 & 9.31 & 0.33 & 0.33 & 0. & 1.00 & 0 & 5 & 5 & $s$ & 0 & 1 \\
\hline J & 15 & 15 & 0 & 0.27 & 0.53 & 0.20 & 0. & 0 & 0. & 6 & 8 & 3 & 0 & 0 \\
\hline 4 & 15 & is & 1 & 0.67 & 0.33 & 0.23 & 0 & 1.00 & 0 & 7 & $s$ & 3 & 0 & 1 \\
\hline > & 15 & 15 & 0 & 0.27 & 0.27 & 0.61 & 0. & 0 & 0. & 4 & 4 & 7 & 0 & 0 \\
\hline 4 & $1:$ & 16 & 1 & 9.16 & 17.06 & $3 .: 1$ & כנכ. & 0. & 0. & 2 & 9 & 3 & 1 & 0 \\
\hline$'$ & 11 & 11 & C & 0.27 & 0.36 & 0.36 & 0. & 0. & 0. & 3 & 4 & 4 & 0 & 0 \\
\hline 3 & 16 & 16 & $J$ & 0.22 & 0.30 & 0.21 & 0. & 0 & 0 & 4 & 7 & 3 & 0 & 0 \\
\hline 7 & ' & 7 & 0 & 0.63 & 0.63 & 0.16 & 0. & 0 & 0. & 3 & 3 & 1 & 0 & 0 \\
\hline 11 & 15 & 15 & $n$ & 0.13 & 3.37 & $13.2 \mathrm{~J}$ & 2 & 0 & 0. & 2 & 10 & 3 & 0 & 0 \\
\hline 11 & 10 & 11 & 0 & 0.10 & 0.63 & $0.5 J$ & 0. & 0 & 0. & 1 & 4 & 5 & 0 & 0 \\
\hline 12 & 12 & 12 & 0 & 3.62 & 0.42 & 0.17 & 0. & 0. & 2. & $s$ & $s$ & 2 & 0 & 0 \\
\hline is & 15 & 13 & 0 & 0.20 & 0.33 & 0.21 & 0. & 0. & 0. & 3 & 9 & 3 & 0 & 0 \\
\hline 16 & 15 & 16 & $\digamma$ & 13.21 & 0.51 & 0.21 & 0. & 0. & 0 & 3 & 8 & 3 & 0 & 0 \\
\hline 15 & $1:$ & 16 & 1) & 3.27 & 0.36 & $n$ & 0. & 0. & 0. & 4 & 9 & 1 & 0 & 0 \\
\hline 13 & 15 & 15 & 0 & 0.27 & 0.07 & 0.07 & 0. & 0 & 0 & 4 & 10 & 1 & 0 & 0 \\
\hline 17 & 15 & 15 & 0 & 3.07 & 0.80 & 0.13 & 3. & 0 & 0 & 1 & 12 & 2 & 0 & 0 \\
\hline 13 & 15 & 15 & 0 & 0.20 & 0.33 & 0.07 & 0. & 0. & 0. & 3 & 11 & 1 & 0 & 0 \\
\hline
\end{tabular}




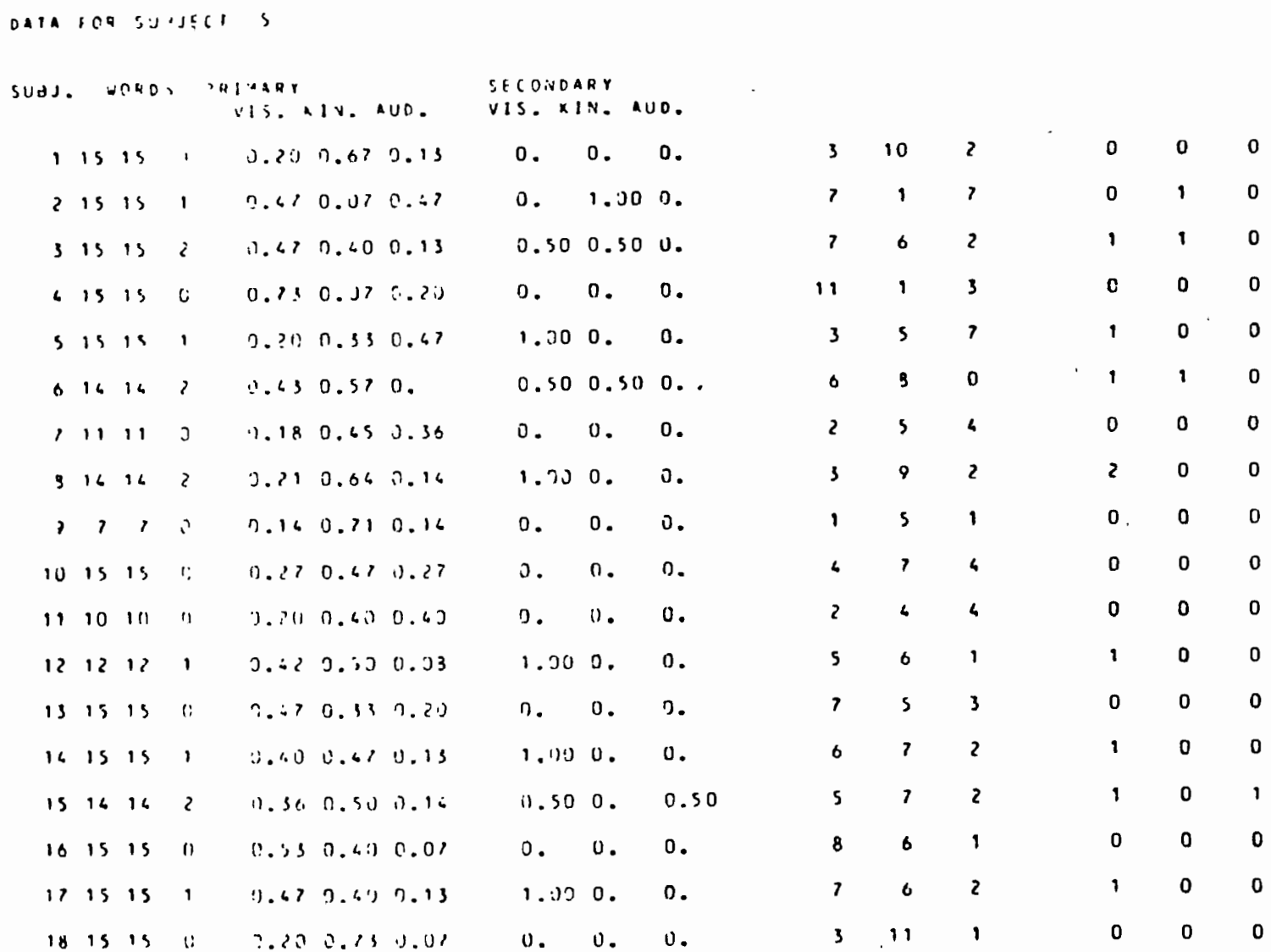


Dara 0 a suafera

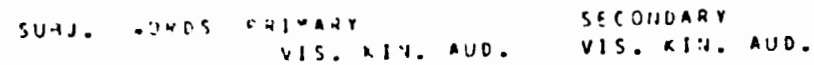

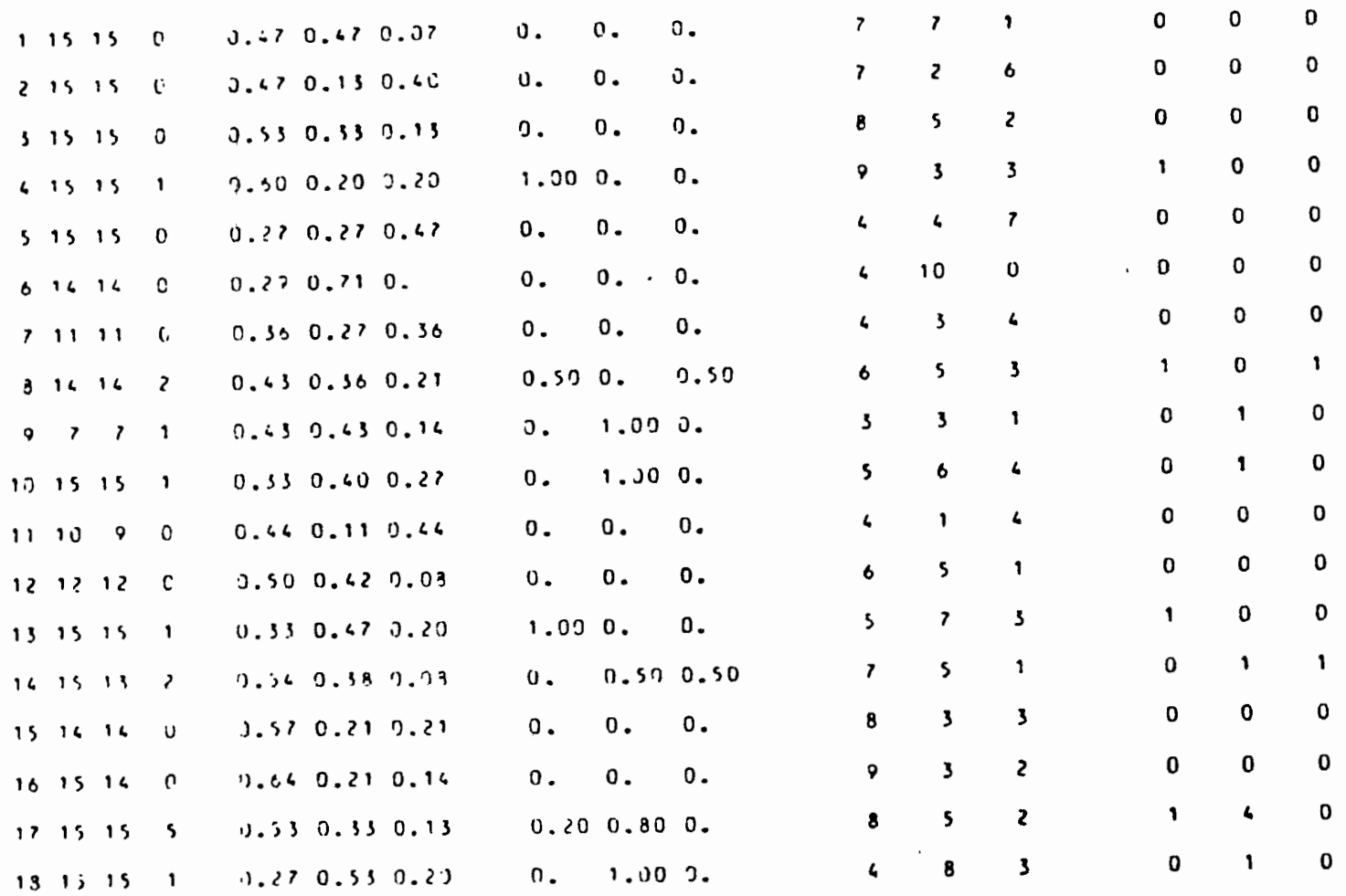




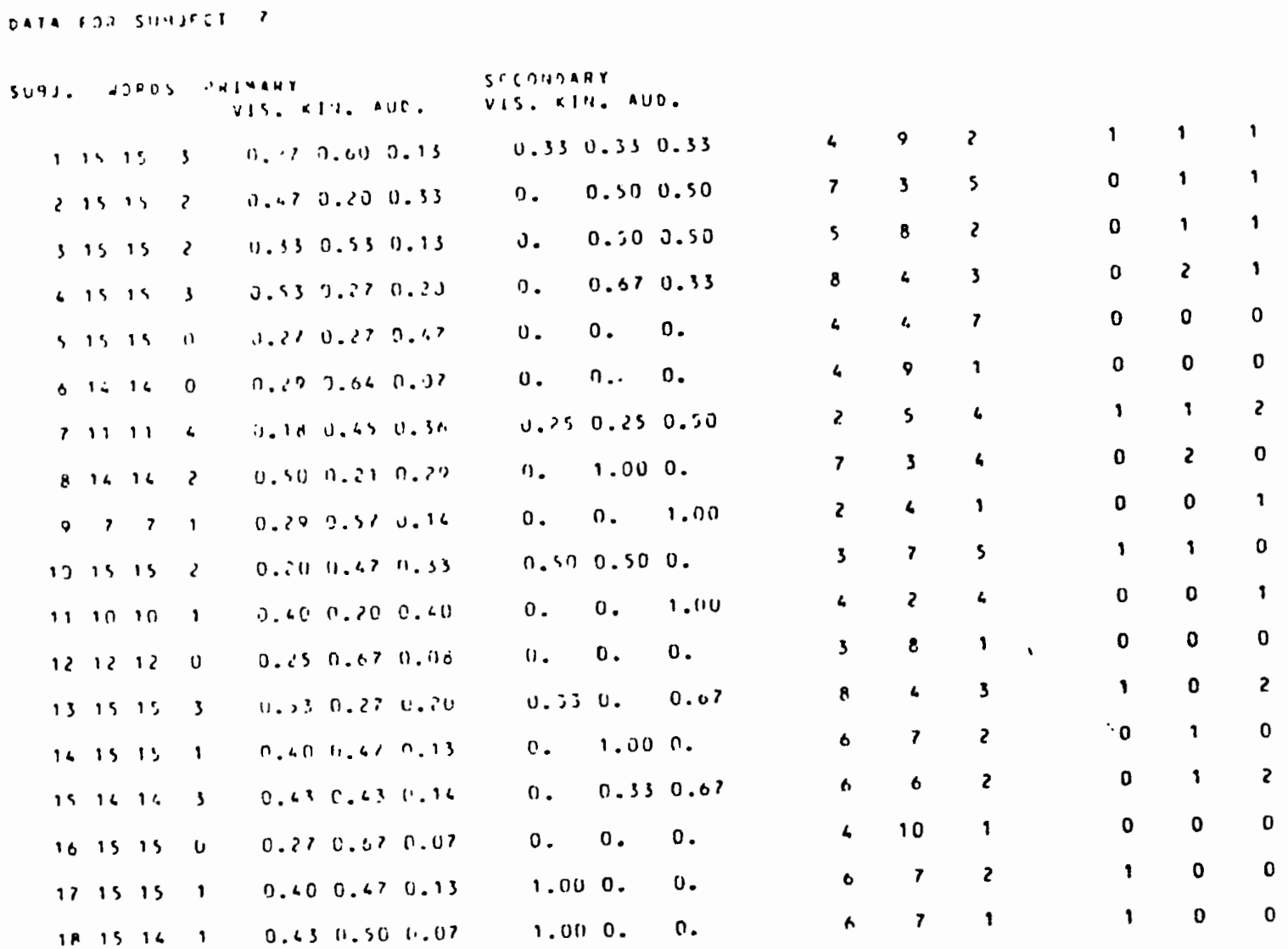


DATA Fi) SUESEC B

SUBJ. DOADS TRIMARY SECONDARY

VIS. I\%. HUD. VIS. KIH. AUD.

\begin{tabular}{|c|c|c|c|c|c|c|c|c|c|c|c|c|c|c|}
\hline 1 & 15 & 15 & 1 & 0.67 & $1) .35$ & 0.07 & 0 & 0 & 1.00 & 4 & $S$ & 1 & 0 & 0 \\
\hline 2 & 15 & 15 & $C$ & 0.20 & 0.27 & 0.53 & 0 & 0 & 0 & 3 & 4 & 8 & 0 & 0 \\
\hline 3 & 15 & 13 & 1 & 0.67 & 0.60 & 0.13 & 1.00 & 0 & 0 & 7 & 0 & 2 & 1 & 0 \\
\hline 4 & 15 & is & 0 & 0.67 & 0.40 & 0.19 & 0. & 0 & 0. & 7 & 6 & 2 & 0 & 0 \\
\hline s & is & 15 & 0 & 7.13 & 0.35 & 0.53 & 0 & 0 & 0 & 2 & 5 & 8 & 0 & 0 \\
\hline 6 & 16 & 16 & 0 & 0.14 & 0.79 & 0.117 & 0 & 0 & 0 & 2 & 11 & 1 & 0 & 0 \\
\hline 7 & 11 & 11 & $C$. & 0.35 & 0.45 & 0.13 & 0 & 0 & 0 & 6 & $s$ & 2 & 0 & 0 \\
\hline 8 & 16 & 14 & $C$ & $\overline{4} .16$ & 0.57 & 0.29 & 0 & 0 & 0 & 2 & 8 & 6 & 0 & 0 \\
\hline$\theta$ & $?$ & 7 & 0 & 5.14 & {$[.71$} & r. .14 & 0 & 0 & 0 & 1 & 5 & 1 & 0 & 0 \\
\hline 10 & 15 & 15 & 2 & 7.13 & 0.40 & $(1.27$ & $c$. & $\mathrm{C}$. & 0 & 5 & 6 & 4 & 0 & 0 \\
\hline 11 & 16 & 10 & 1 & 0.20 & 0.60 & C. . >0 & 0. & 0 & 1.00 & 2 & 6 & 2 & 0 & 0 \\
\hline 17 & 12 & 12 & $\mathrm{G}$ & 0.62 & 0.50 & (1. (I) & 0 & 0 & 0 & 5 & 6 & 1 & 0 & 0 \\
\hline 13 & 15 & 15 & $U$ & 0.40 & C. 33 & 0.27 & 0 & 0. & 0 & 6 & 5 & 4 & 0 & 0 \\
\hline 14 & 15 & 15 & 0 & 11.33 & 0.67 & 0.20 & 0. & 0 & 0 & 5 & 7 & 3 & 0 & 0 \\
\hline 15 & 16 & 16 & 1 & $\therefore 71$ & 0.21 & 0.07 & 0 & 0. & 1.00 & 10 & 3 & 1 & 0 & 0 \\
\hline 16 & 15 & 15 & 3 & 0.53 & 0.60 & 0.07 & 0 & 0 & 0 & 8 & 6 & 1 & 0 & 0 \\
\hline 17 & 15 & 15 & 0 & $(3.60)$ & 0.60 & $c .2 \mathrm{C}$ & 0 & 0 & 0 & 6 & 6 & 3 & 0 & 0 \\
\hline 19 & 15 & is & 0 & 0.27 & 0.23 & 0.20 & 0 & 0 & 0. & 6 & 8 & 3 & $U$ & 0 \\
\hline
\end{tabular}




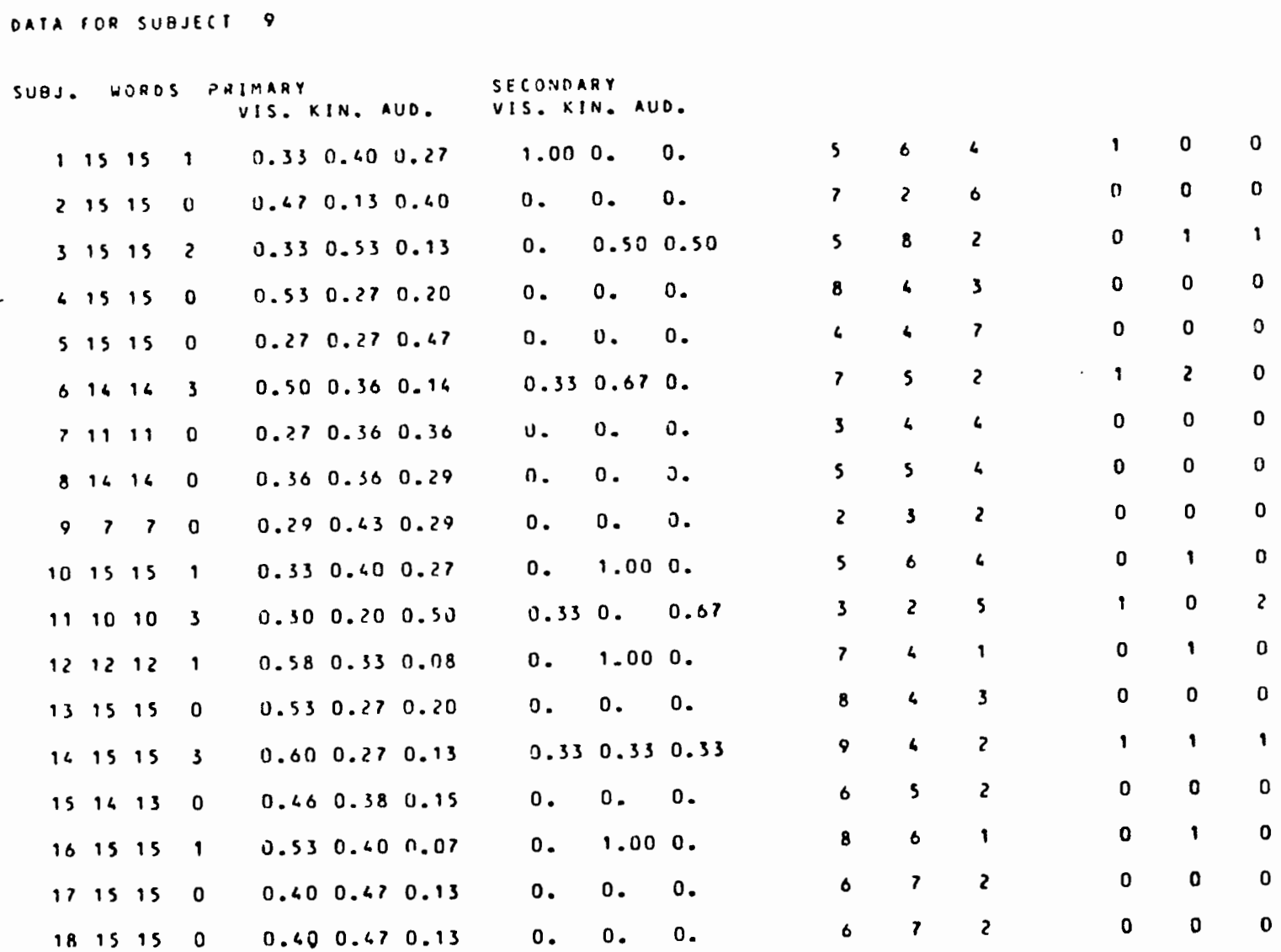


DATR FOR SUEJECP 10

SUBJ. WOROS PRITARY SECONDARY

VIS. KIN. AUD. VIS.KIN. AUD.

1 is is 0 0. $0.300 .20 \quad 0.0 .0$.

2 is is $10.200 .400 .40 \quad 0.0 .1 .00$

$3151510.200 .070 .13 \quad 1.000 .00$

4 15 150

$0.330 .530 .13 \quad 0.0 .0$.

is 15 is 0

0.270 .330 .40

D. 0.0 .

614141

0.140 .710 .14

0.1 .000 .

711110

0.180 .450 .36

o. 0.0 .

$81414 \quad 0$

0.210 .570 .21

0 . 0.0 .

9770

0.140 .710 .16

0 . 0.0 .

10 is is 0

0.070 .730 .20

0. 0.0 .

1110100

0.100 .700 .20

o. 0.0 .

1212120

$0.170 .75 \quad 0.08$

0 . 0.0 .

1315150

0.200 .530 .27

o. 0.0 .

16 is is 0

0.270 .800 .13

o. 0.0 .

$15 \quad 14 \quad 14 \quad 0$

0.360 .500 .14

U. 0.0 .

16 is is 1

0.200 .730 .07

1.000 .0 .

$17 \quad 1515 \quad 0$

0.070 .730 .20

o. 0.0 .

$\begin{array}{llll}18 & 15 & 15 & 1\end{array}$

0.070 .300 .13

1.000 .0 .

$\begin{array}{llllll}0 & 12 & 3 & 0 & 0 & 0 \\ 3 & 0 & 0 & 0 & 0 & 1 \\ 3 & 10 & 2 & 1 & 0 & 0 \\ 5 & 8 & 2 & 0 & 0 & 0 \\ 6 & 5 & 0 & 0 & 0 & 0 \\ 2 & 10 & 2 & 0 & 1 & 0 \\ 2 & 5 & 6 & 0 & 0 & 0 \\ 3 & 0 & 3 & 0 & 0 & 0 \\ 1 & 5 & 1 & 0 & 0 & 0 \\ 1 & 11 & 3 & 0 & 0 & 0 \\ 1 & 7 & 2 & 0 & 0 & 0 \\ 2 & 9 & 1 & 0 & 0 & 0 \\ 3 & 8 & 4 & 0 & 0 & 0 \\ 4 & 9 & 2 & 0 & 0 & 0 \\ 3 & 7 & 2 & 0 & 0 & 0 \\ 3 & 11 & 1 & 1 & 0 & 0 \\ 1 & 11 & 3 & 0 & 0 & 0 \\ 1 & 12 & 2 & 0 & 0\end{array}$


DATA FOR SUEJECT 11

SUGJ. WORDS PRIMAKY SECONDARY
VIS. KIH. AIJD. VIS. KIN. RUO.

\begin{tabular}{|c|c|c|c|c|c|c|c|c|c|c|c|c|c|c|}
\hline 1 & 15 & 15 & 1 & 0.60 & 0.53 & 0.07 & 1.00 & 0 & 0 & s & 8 & 1 & 1 & 0 \\
\hline 2 & 15 & 14 & 0 & 0.29 & 0.36 & 0.36 & 0 & 0. & 0 & 4 & $s$ & $s$ & 0 & 0 \\
\hline 3 & 15 & is & 0 & 0.53 & 0.33 & 0.13 & 0 & 0 & 0. & 8 & 5 & 2 & 0 & 0 \\
\hline 6 & 15 & 15 & 0 & 0.60 & 0.40 & 0 & 0 & 0. & 0 & 9 & 0 & 0 & 0 & 0 \\
\hline 5 & 15 & 15 & 0 & 0.33 & 0.33 & 0.33 & 0 & 0 & 0 & 5 & 5 & $s$ & 0 & 0 \\
\hline 6 & 16 & 16 & 0 & 0 & 1.00 & $n$ & 0 & 0 & 0 & 0 & 16 & 0 & 0 & c \\
\hline 7 & 11 & 11 & 0 & 0.18 & 0.45 & 0.36 & 0 & 0 & 0 & 2 & $s$ & 6 & 0 & 0 \\
\hline 8 & 16 & 16 & 1 & 0.29 & 0.43 & 0.29 & 0. & 1.00 & 0 & 4 & 6 & 4 & 0 & 1 \\
\hline 9 & 7 & 7 & 0 & 0.24 & 0.57 & 0.14 & 0 & 0 & 0 & 2 & 4 & 1 & 0 & 0 \\
\hline 10 & is & 14 & 2 & 0.14 & 0.64 & 0.21 & 0.50 & 0.50 & 0 & 2 & 9 & 3 & 1 & 1 \\
\hline 11 & 10 & 10 & 1 & 0.40 & 0.30 & 0.30 & 1.00 & 0 & 0. & 4 & 3 & 3 & 1 & 0 \\
\hline 12 & 12 & 12 & 0 & 0.50 & 0.42 & 0.08 & 0 & 0 & 0 & 6 & $s$ & 1 & 0 & 0 \\
\hline 13 & 15 & 15 & 0 & 0.53 & 0.40 & 0.07 & 0 & 0 & 0. & $x$ & 0 & 1 & 0 & 0 \\
\hline 16 & 15 & 15 & 2 & 0.60 & 0.47 & 0.13 & 0.50 & 0.50 & 0. & 6 & 7 & 2 & 1 & 1 \\
\hline 15 & 14 & 14 & 0 & 0.36 & 0.57 & 0.177 & 0 & 0 & $u$ & $s$ & $B$ & 1 & 0 & 0 \\
\hline 16 & 15 & 15 & 2 & 0.53 & 0.40 & 0.07 & 0.50 & 0.50 & o. & 8 & 6 & 1 & 1 & 1 \\
\hline 17 & 15 & 15 & 0 & 0.40 & 0.40 & 0.20 & 0 & 0 & 0. & 0 & 6 & 3 & 0 & 0 \\
\hline 18 & 15 & 16 & 1 & 0.30 & 0.50 & 0.14 & 1.00 & 0 & 0. & $s$ & 7 & 2 & 1 & 0 \\
\hline
\end{tabular}


OAIA FOR SUBJECT 12

SUOJ. WOROS PRIMARY
VIS. KIN. AUD. VEONDARY
VIS. KIN. AUD.

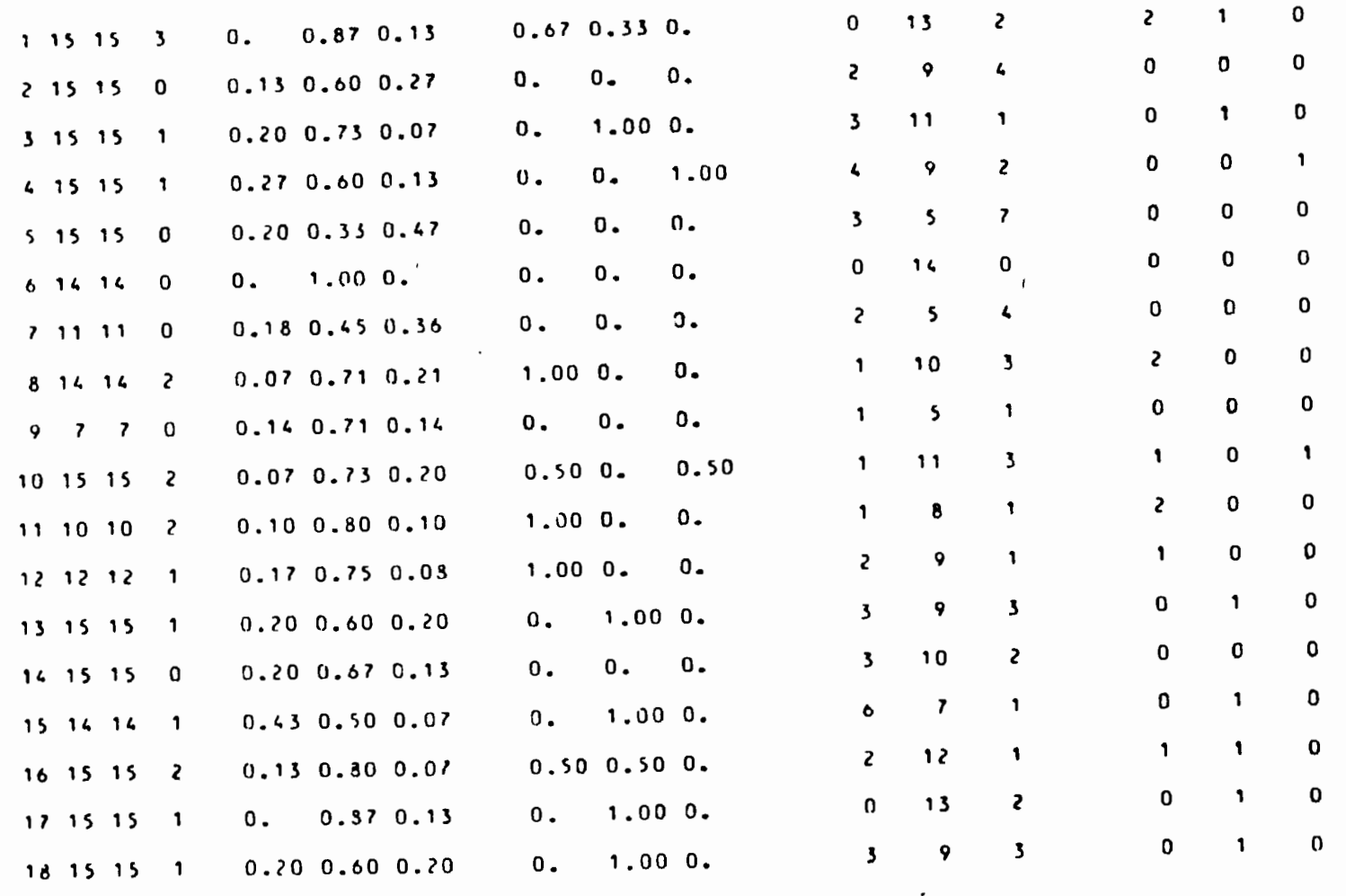


oAta for suajegt is

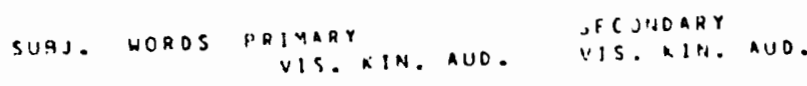

\begin{tabular}{|c|c|c|c|c|c|c|c|c|c|c|c|c|c|}
\hline 1 & is 1 & 15 & 2 & 0.40 & 0.470 .13 & 0.50 & 0.50 & 0 & 6 & 7 & 2 & 1 & 1 \\
\hline 2 & 15 & 15 & 0 & 0.47 & 0.200 .33 & 0 & 0 & 0 & 7 & 3 & $s$ & 0 & 0 \\
\hline 3 & is & is & 2 & 0.47 & 0.600 .13 & 0.50 & 0.50 & 0 & 7 & 6 & 2 & 1 & 1 \\
\hline 4 & 15 & 15 & 0 & 0.73 & 0.130 .13 & 0. & 0. & 0 & 11 & 2 & 2 & 0 & 0 \\
\hline 5 & 15 & 15 & 0 & 0.27 & 0.330 .43 & 0. & 0 & 0 & 4 & $s$ & 6 & 0 & 0 \\
\hline 6 & 14 & 16 & 0 & $0 .<3$ & 0.570. & 0. & 0. & 0. & $b$ & 8 & 0 & 0 & 0 \\
\hline 7 & 11 & 11 & 0 & 0.27 & $0.36 \quad 0.36$ & 0 & 0 & 0 & 3 & 4 & 4 & 0 & 0 \\
\hline 8 & 14 & 16 & 0 & 0.71 & 0.210 .07 & 0. & 0 & 0. & 10 & 3 & 1 & 0 & D \\
\hline 9 & 7 & $?$ & 0 & 0.20 & 0.370 .16 & 0. & 0 & 0. & 2 & 4 & 1 & 0 & 0 \\
\hline 10 & 15 & 15 & 0 & 0.07 & $9.27 \quad 0.13$ & 0. & 0 & 0. & 9 & 4 & 2 & 0 & 0 \\
\hline 11 & 10 & 10 & 1 & 0.40 & 0.500 .10 & 1.00 & 0 & 0. & 4 & 5 & 1 & 1 & 0 \\
\hline 12 & 12 & 12 & 1 & 0.50 & 0.420 .08 & 0. & 1.00 & 0 & 6 & 5 & 1 & 0 & 1 \\
\hline 13 & 15 & 15 & 0 & $0.0 ?$ & 11.330. & 0. & 0. & 0. & 10 & 5 & 0 & 0 & 0 \\
\hline 16 & 15 & is & 0 & 0.53 & $0.60 \quad 0.07$ & 0 & 0. & 0. & 8 & 6 & $?$ & 0 & 0 \\
\hline 15 & 14 & 14 & 1 & 0.37 & 0.210 .21 & 1.00 & 0 & 0 & 8 & 3 & 3 & 1 & 0 \\
\hline 16 & 15 & 15 & 1 & 0.67 & 0.330. & 0 & 1.00 & 0 & 10 & 5 & 0 & 0 & 1 \\
\hline 17 & 15 & 15 & 0 & 0.60 & 0.270 .13 & 0 & 0 & 3. & 9 & 4 & 2 & 0 & 0 \\
\hline 18 & 15 & 15 & 1 & 0.33 & 0.670. & 0 & 0 & 1.00 & 5 & 10 & 0 & 0 & 0 \\
\hline
\end{tabular}


DATA IOR SUBJECT 16

SUAJ. WOROS PHIMARY SECONDARY

VIS. KIN. AUD. VIS. KIN. AUD.

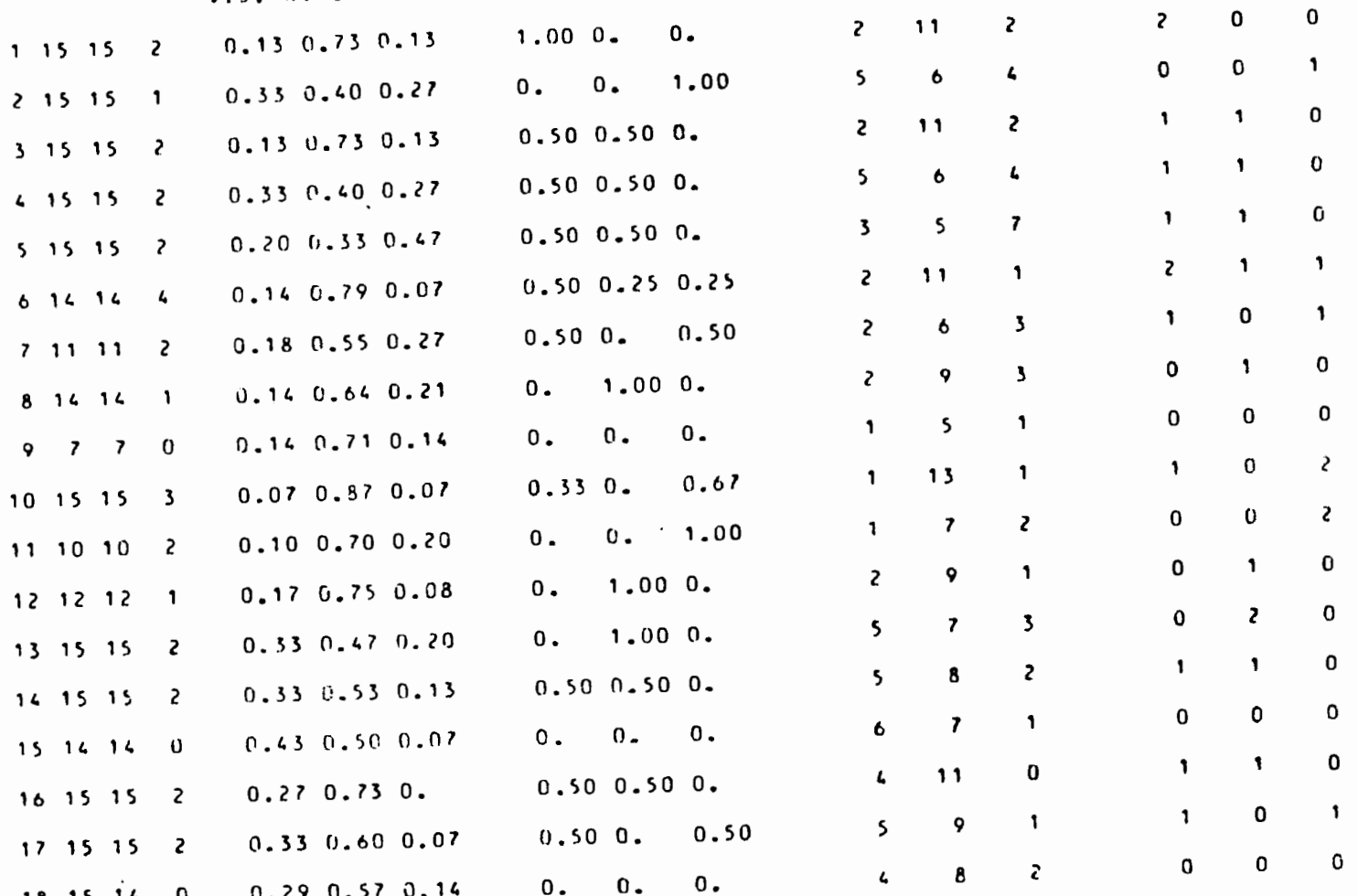




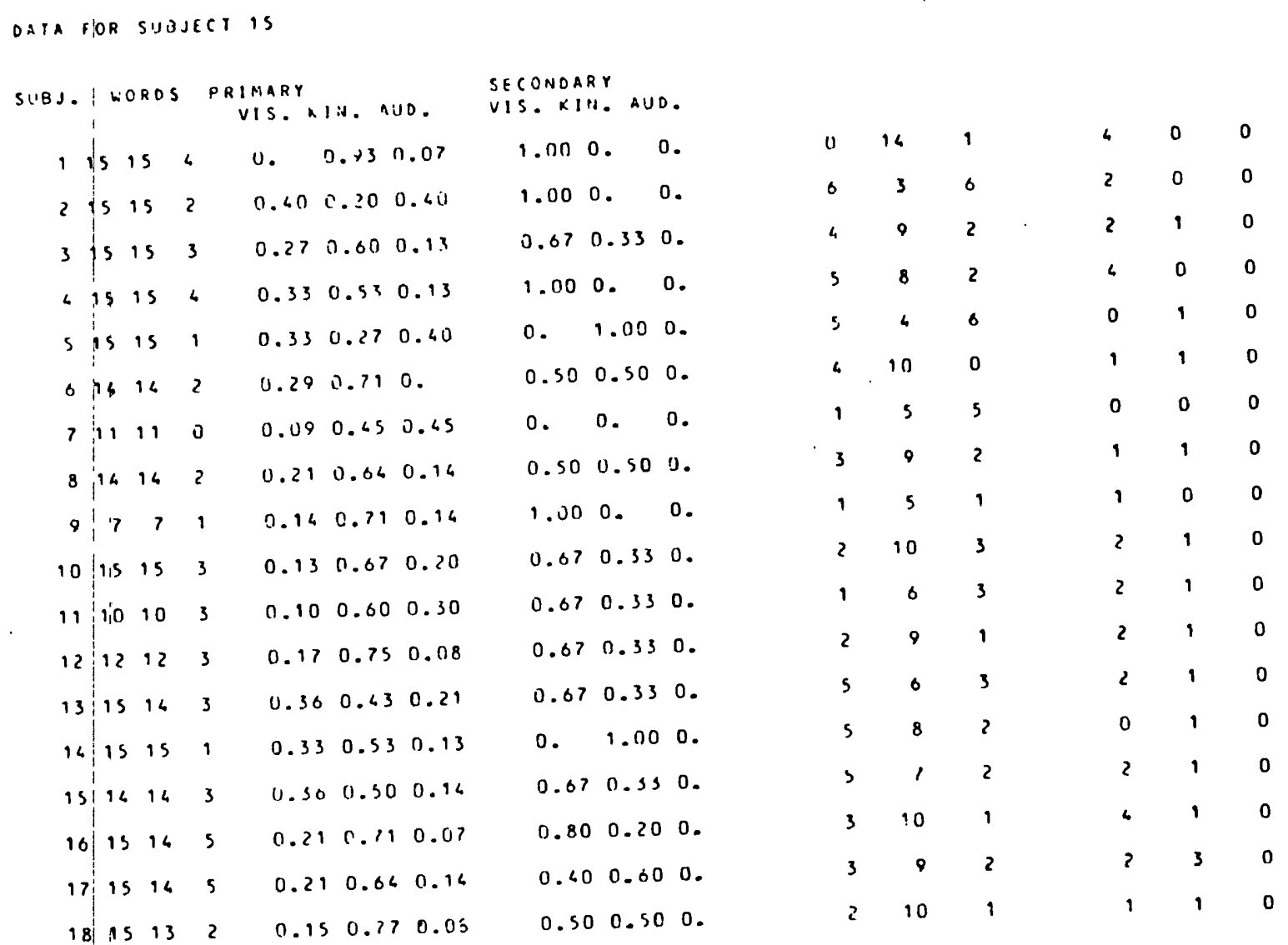


DATA FOR SUEJECT IS

SHBJ. WORDS PRIMARY SECONDARY
VIS.KIN. AUU. VIS. KIN. AUD.

\begin{tabular}{|c|c|c|c|c|c|c|c|c|c|c|c|c|c|c|}
\hline 10 & As & 15 & 1 & 0.27 & 0.67 & 0.07 & 0 & 1.00 & 0 & 4 & 10 & 1 & 0 & 1 \\
\hline 2 & 15 & 15 & 1 & 0.47 & 1.. 27 & 0.27 & 0 & 1.30 & 0 & 7 & 4 & 6 & 0 & 1 \\
\hline 3 & 15 & 15 & 4 & 0.53 & 0.27 & 0.20 & 0.25 & 0.50 & 0.25 & 8 & 4 & 3 & 1 & 2 \\
\hline 4 & 15 & 15 & 6 & 0.80 & 0.07 & 0.13 & 0. & 0.75 & 0.25 & 12 & 1 & 2 & 0 & 3 \\
\hline 5 & 15 & 15 & 1 & 0.27 & 0.27 & 0.47 & 0 & 1.00 & 0. & 4 & 6 & 7 & 0 & 1 \\
\hline 6 & 16 & 14 & 2 & 0.36 & 0.34 & 0. & 0.50 & 0.50 & 0. & ; & 9 & 0 & 1 & 1 \\
\hline 7 & 11 & 11 & 1 & 0.09 & 0.55 & 0.36 & 1.00 & 0 & 0. & 1 & 6 & 6 & 1 & 0 \\
\hline & & 16 & 3 & 0.29 & 0.57 & 0.14 & 0.33 & 0.67 & 0 & 6 & 6 & 2 & 1 & 2 \\
\hline 9 & 7 & 7 & 3 & 0.14 & 0.71 & 0.14 & 0.33 & 0.67 & 0 & 1 & 5 & 1 & 1 & 2 \\
\hline $10^{1}$ & 15 & 15 & 1 & 0.20 & 0.67 & 0.13 & 1.00 & 0 & 0 & 3 & 10 & 2 & 1 & 0 \\
\hline 11 & 10 & 10 & 1 & 0.30 & 0.30 & 0.40 & 1.00 & 0 & 0. & 3 & 3 & 4 & 1 & 0 \\
\hline 12 & 12 & 12 & 2 & 0.50 & 0.33 & 0.17 & 0 & 1.00 & 0 & 6 & 4 & 2 & 0 & 2 \\
\hline 13 & 15 & 14 & 2 & 0.36 & 0.43 & 0.21 & 0.50 & 0 & 0.50 & 5 & 6 & 3 & 1 & 0 \\
\hline 14 & 15 & 15 & 2 & 0.53 & 0.33 & 0.13 & 0. & 1.00 & 0 & 8 & 5 & 2 & 0 & 2 \\
\hline 15 & 14 & 16 & $?$ & 0.57 & 0.29 & 0.14 & 0 & 0.50 & 0.50 & 8 & 4 & 2 & 0 & 1 \\
\hline 16 & 15 & 15 & 1 & 0.53 & 0.40 & 0.07 & 1.00 & 0. & 0. & 8 & 0 & 1 & 1 & 0 \\
\hline 17 & 15 & 14 & 1 & 0.50 & 0.29 & 0.21 & 0 & 0 & 1.00 & 7 & 4 & 3 & 0 & 0 \\
\hline 18 & 15 & 14 & 1 & 0.29 & 0.66 & 0.07 & 1.00 & 0 & 0. & 4 & 9 & 1 & 1 & 0 \\
\hline
\end{tabular}


DATA FOR SUPJECI 17

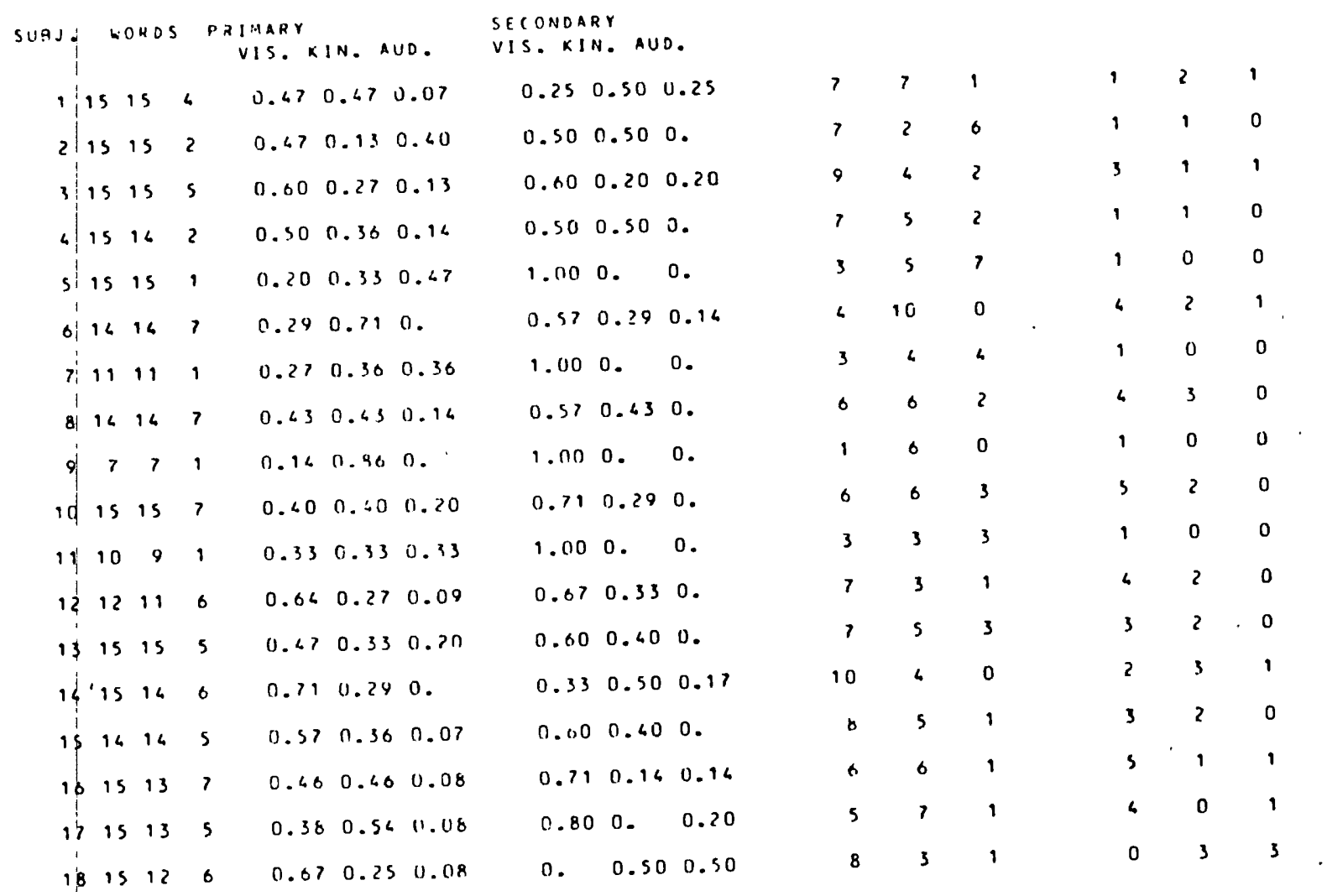


DATA BPR SUGJECT 18

SUEJ. WORDS PRI:IARY
VIS. RIN. AUD. VEONDARY
VIS. AIR. AUO.

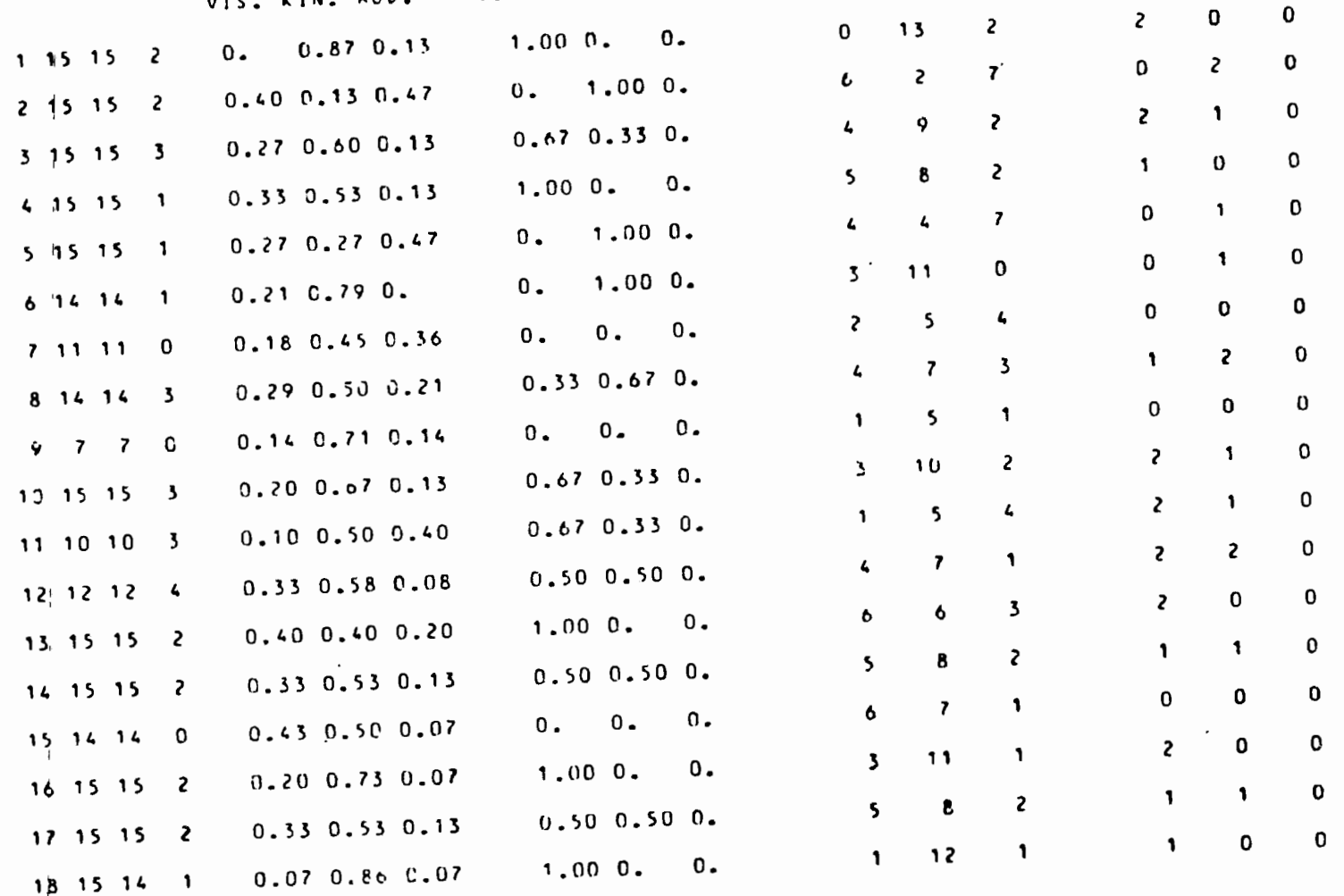


APPENDIX E

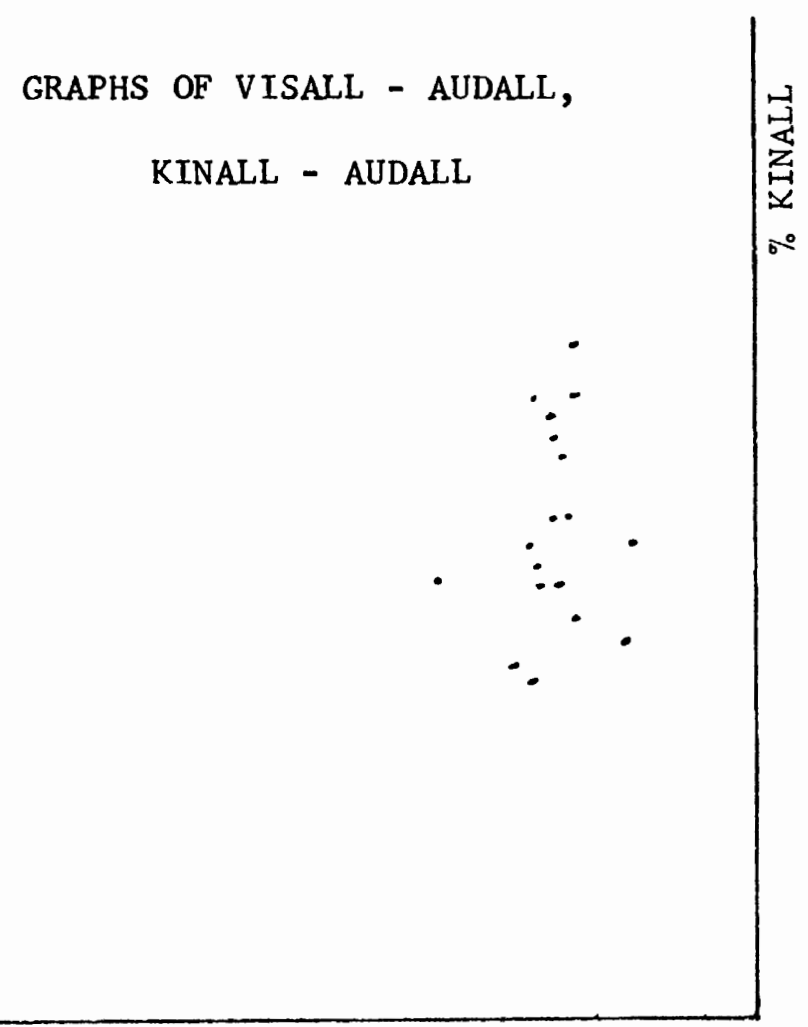

$\%$ AUDALL

$\%$ AUDALL 


\begin{tabular}{|c|c|}
\hline & ; \\
\hline & 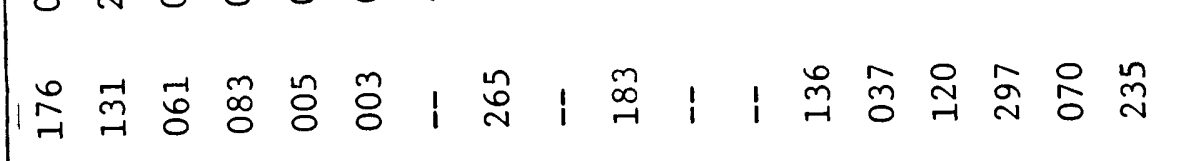 \\
\hline & 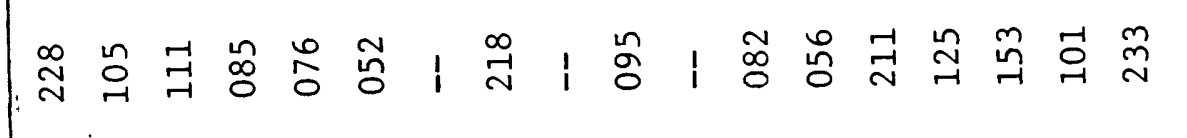 \\
\hline & 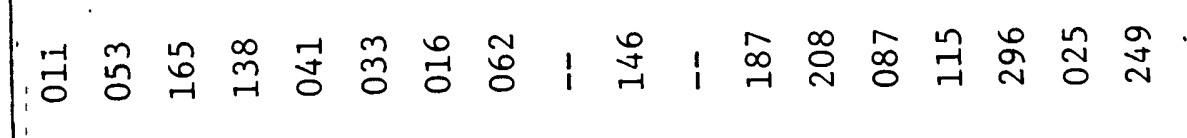 \\
\hline & 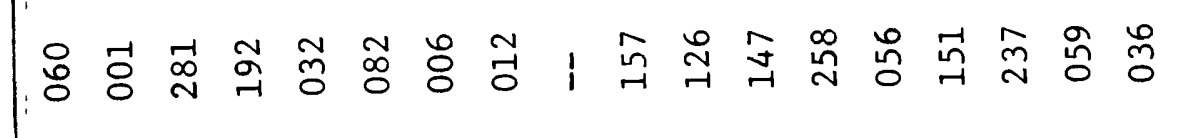 \\
\hline$a$ & 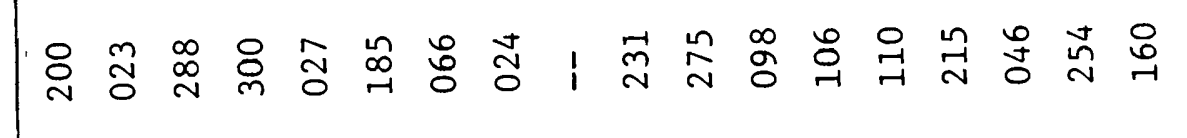 \\
\hline & 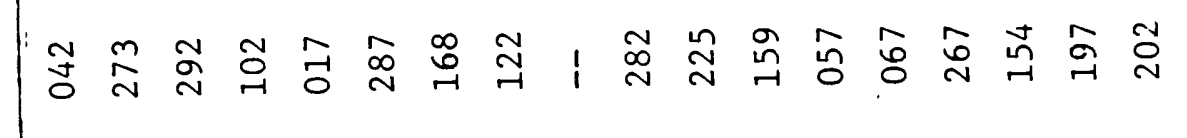 \\
\hline 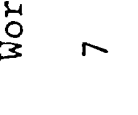 & 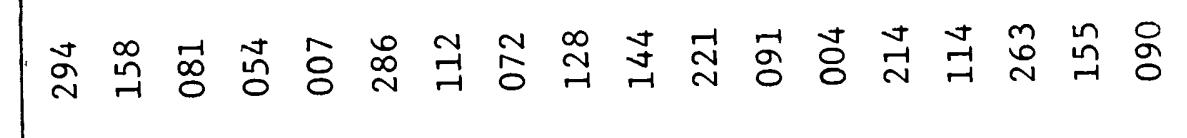 \\
\hline & 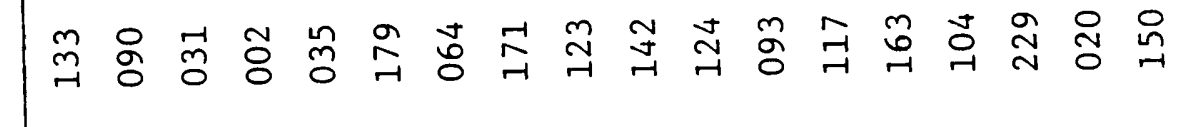 \\
\hline & 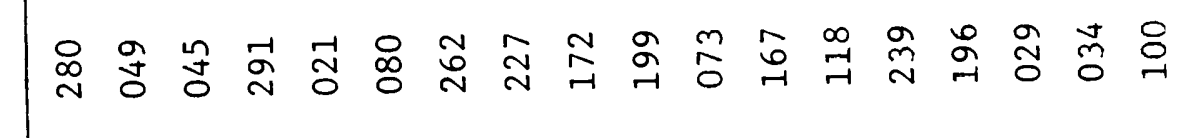 \\
\hline & 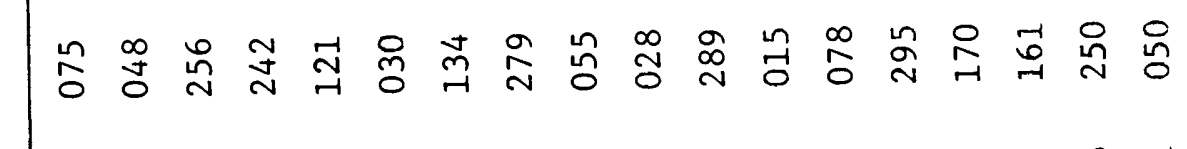 \\
\hline & 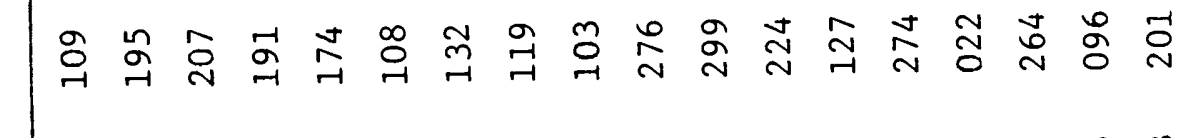 \\
\hline & 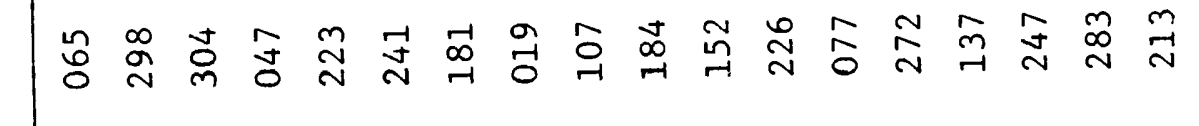 \\
\hline & 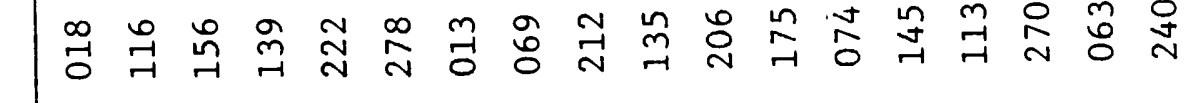 \\
\hline & 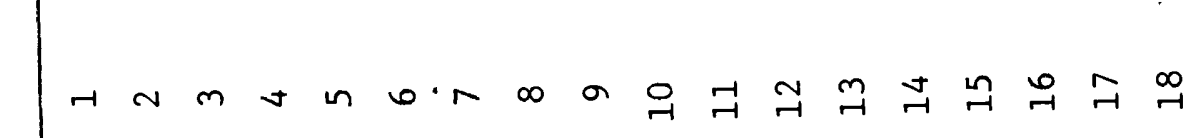 \\
\hline
\end{tabular}




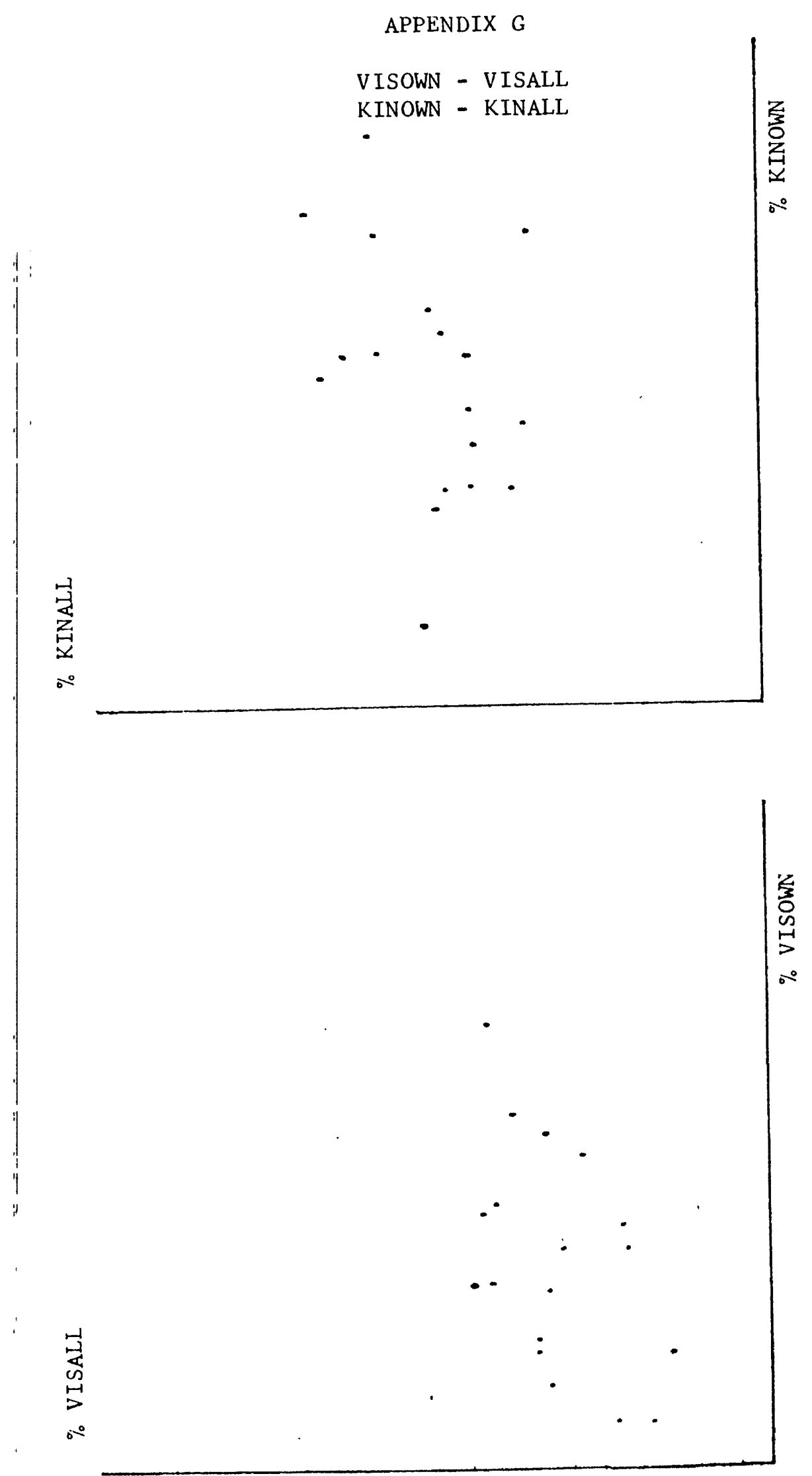




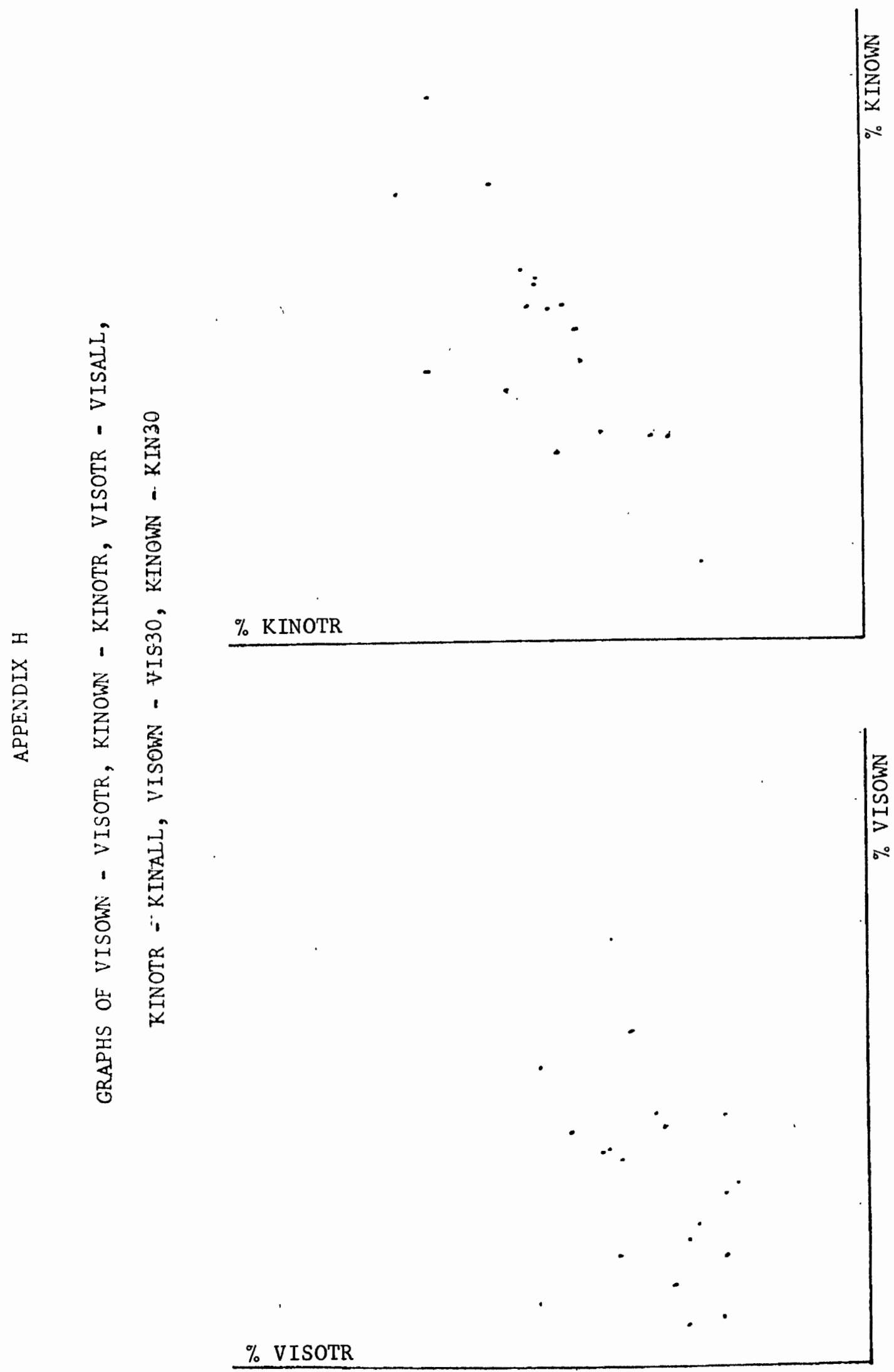




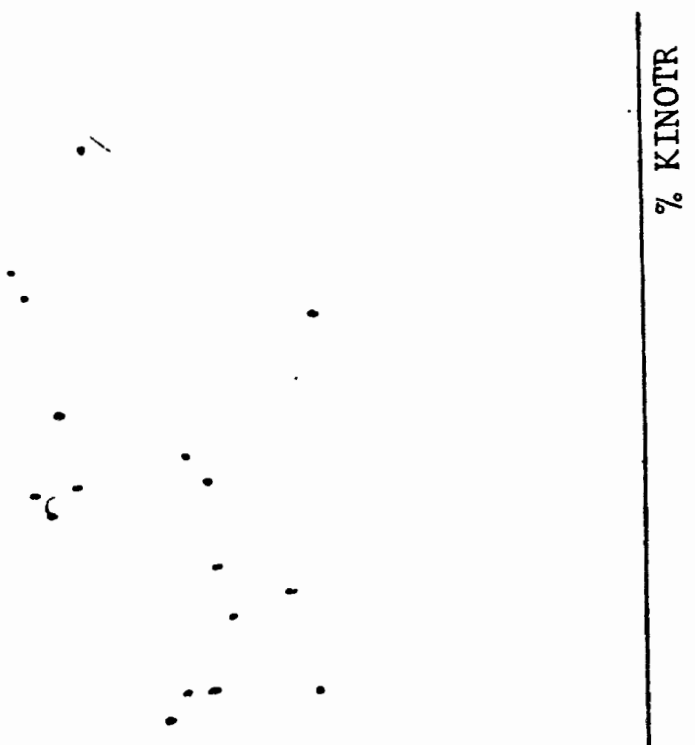

$\%$ KINALL

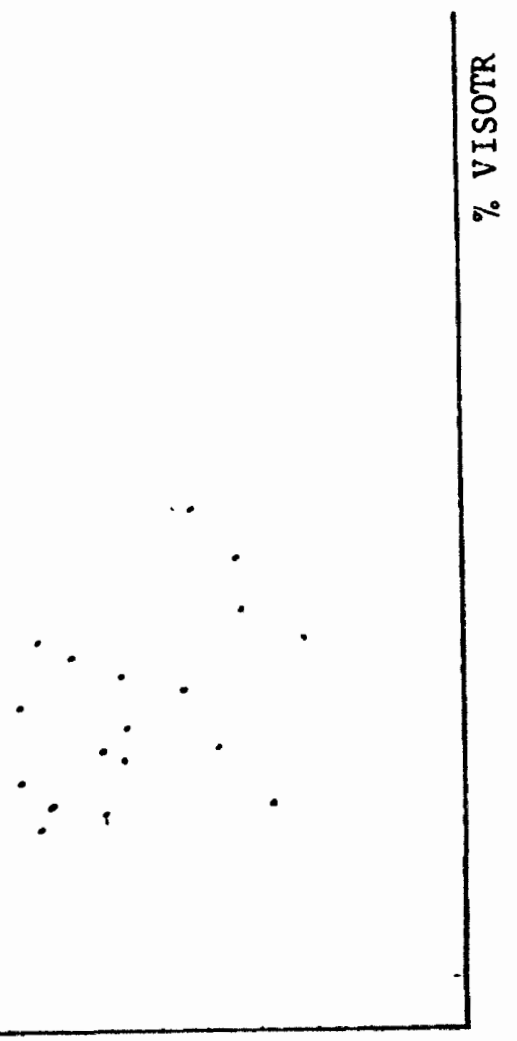




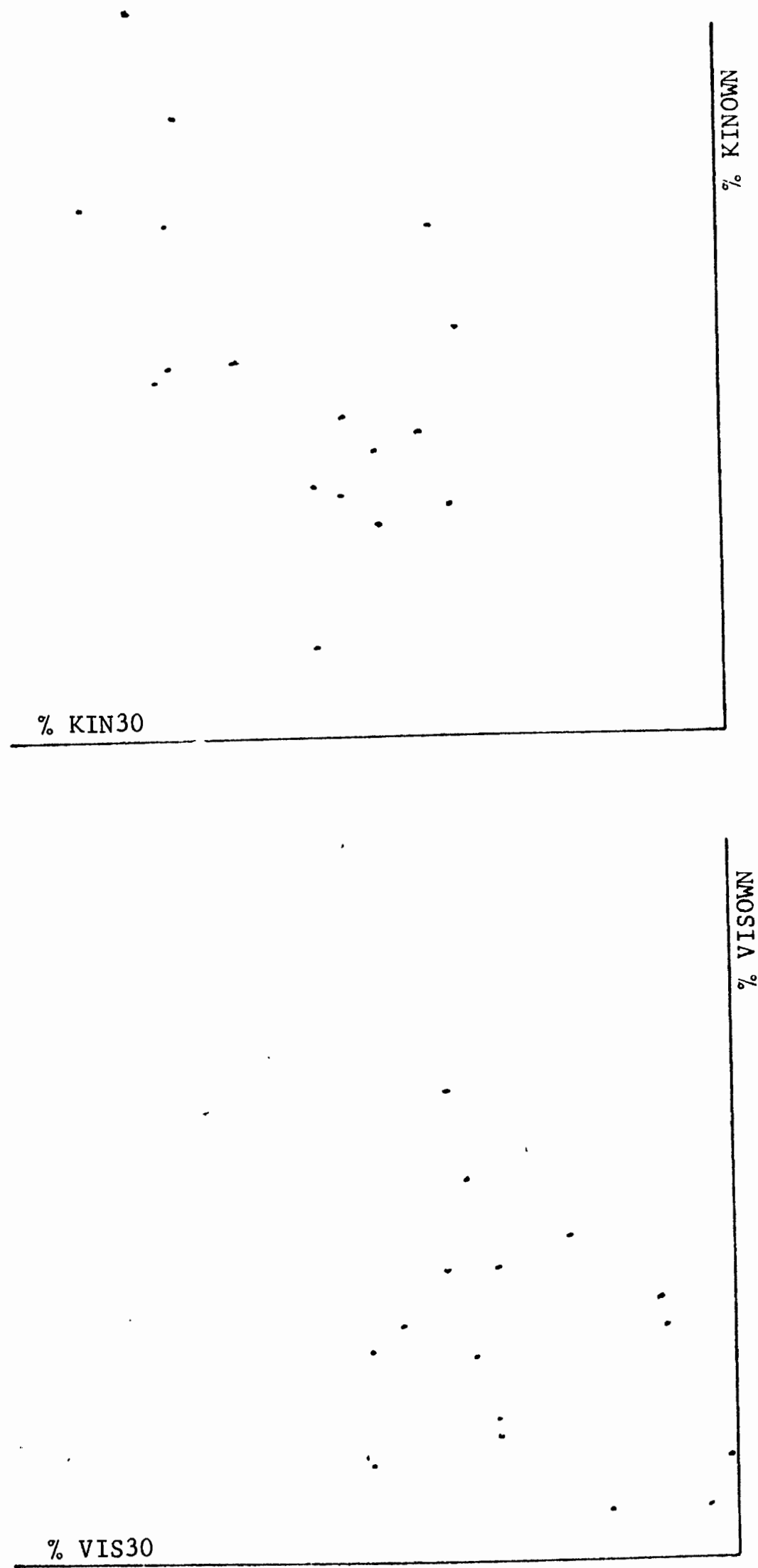


APPENDIX I

TABULATION OF RESPONSE CATEGORIES BY WORD NUMBER

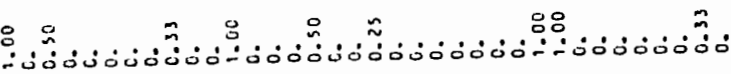

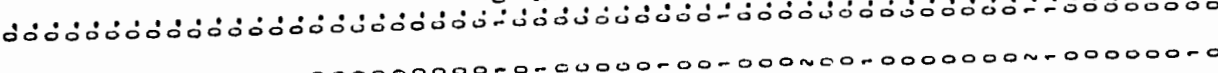
$000000000000000000000000-00000000000000 n$

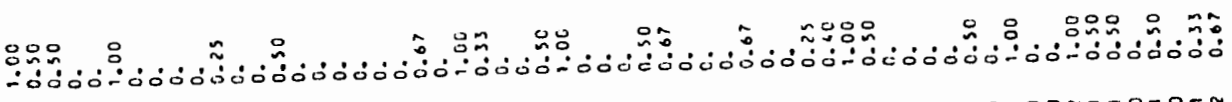

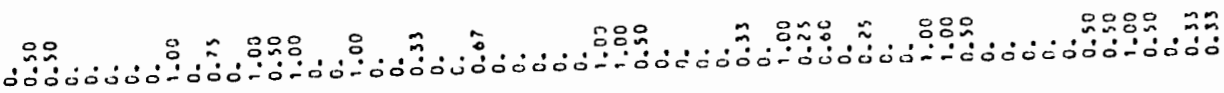

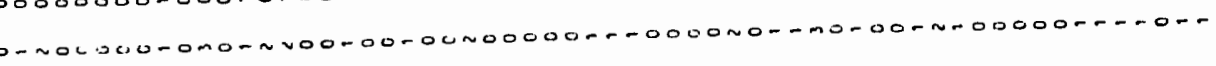

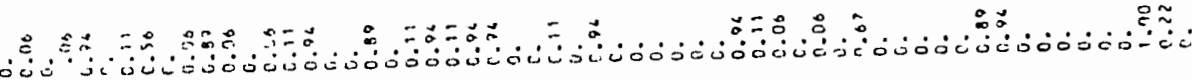

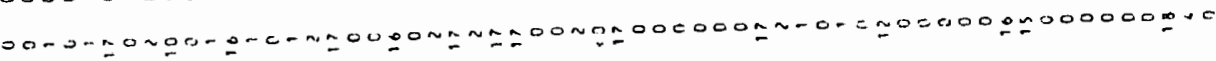

$=\geq ₹ 5$.

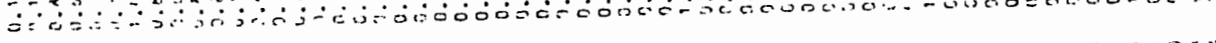

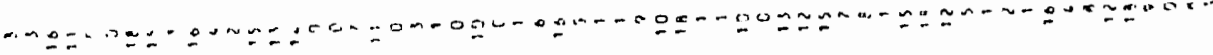

$=x_{0}$

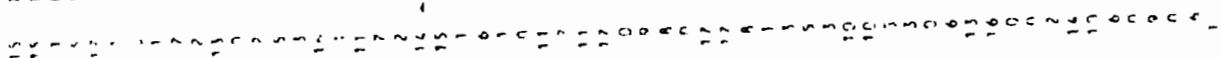

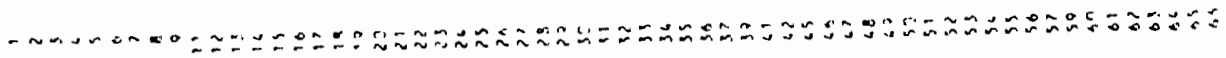




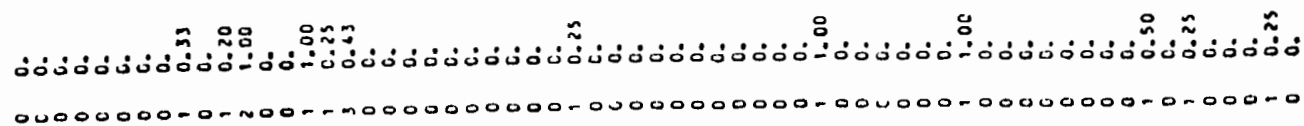

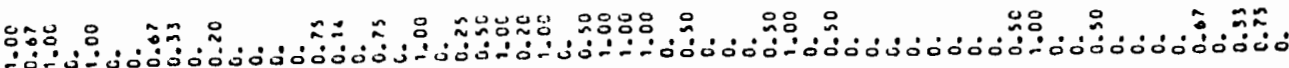

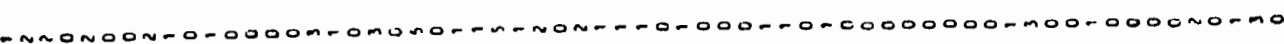

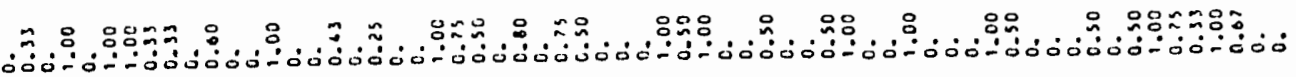

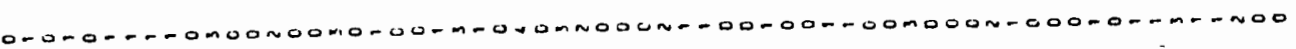

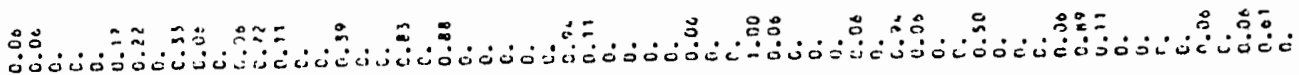

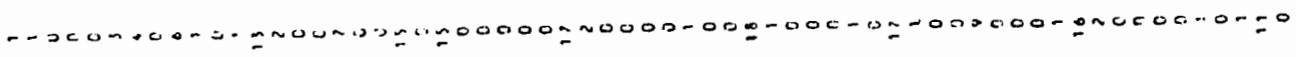

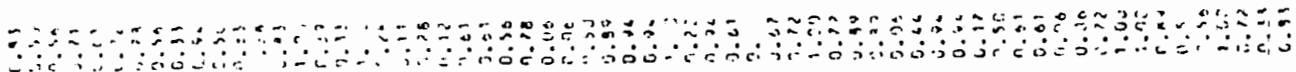

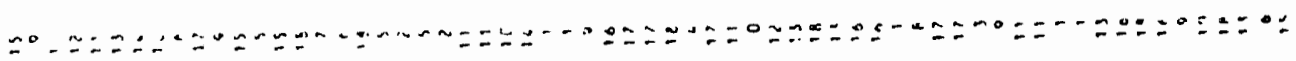

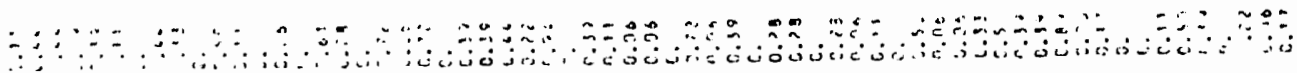

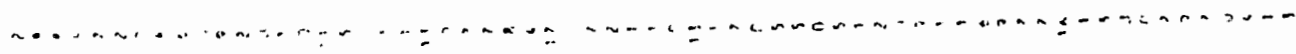

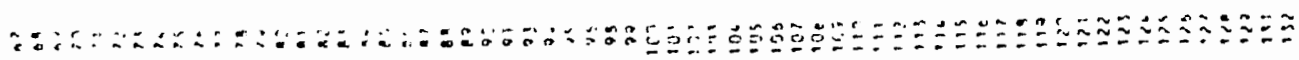




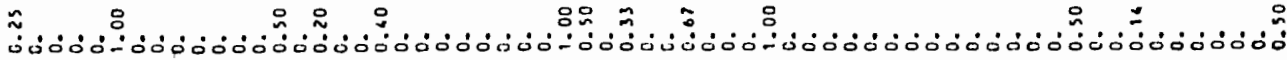
-0000-0000000-0-00 00000000 N0-00N000-00000000000000-000000000-

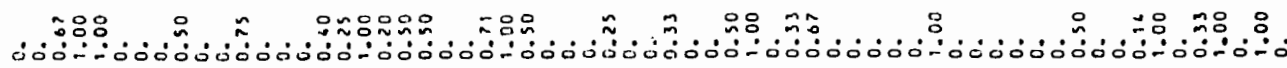

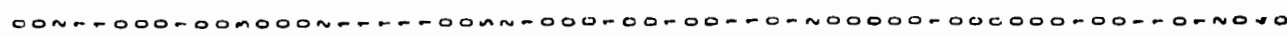

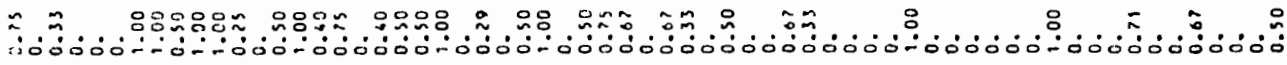

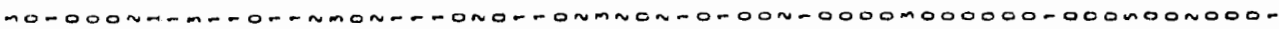

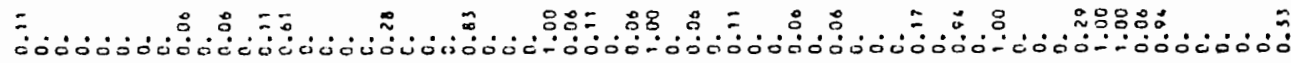

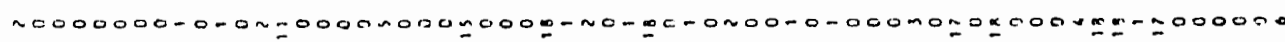

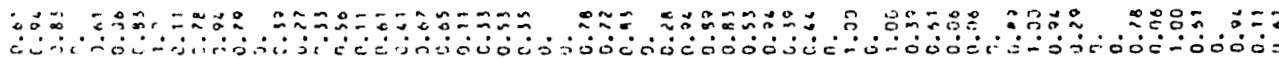

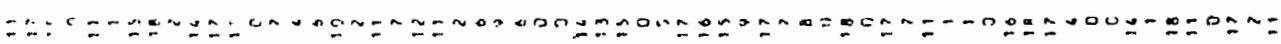

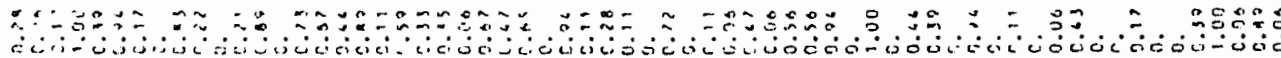

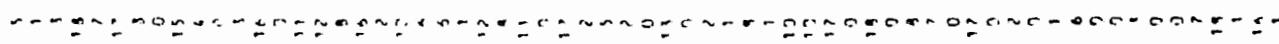

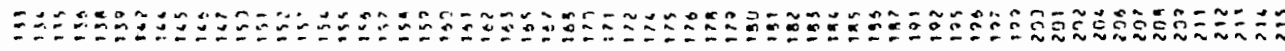




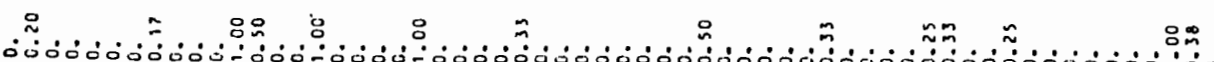

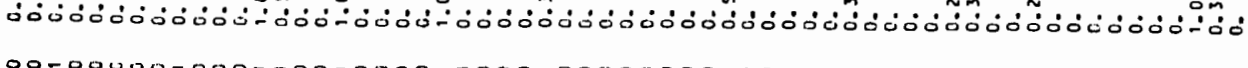

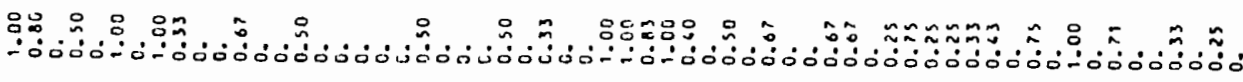
- vo-0monnoonoo-00000-0uo-0-00--n-no-0noonno-m---momononoo-0no

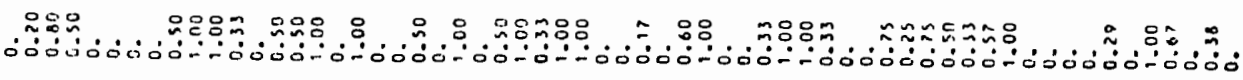

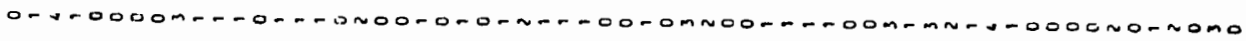

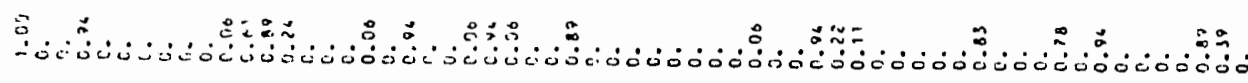

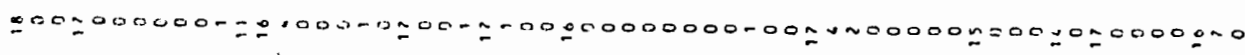

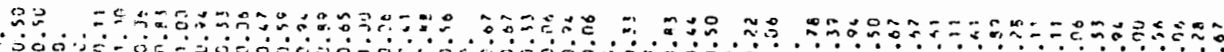

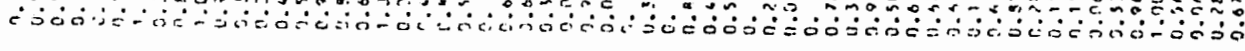

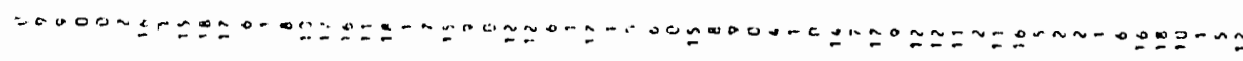

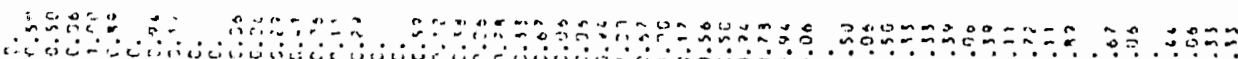

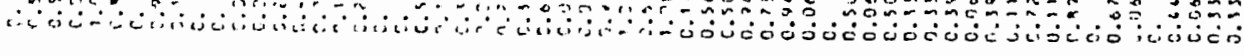

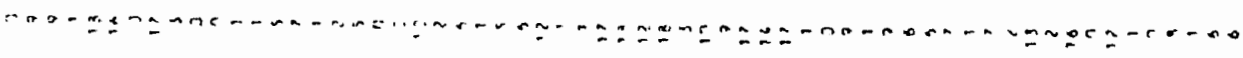

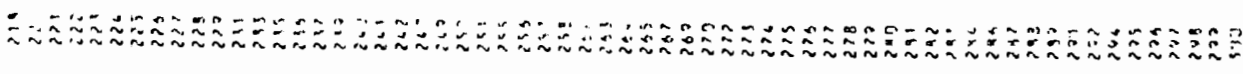


